\title{
Anchoring Carboxyl Functionalized Gold-Aryl Nanoparticles to Graphene Oxide Platforms for Environmental Nanoremediation
}

\author{
Javad B. M. Parambath, ${ }^{\text {a }}$ Najrul Hussain, ${ }^{\text {b }}$ Mahreen Arooj, ${ }^{a}$ Maria Omastova, ${ }^{c}$ \\ Mohamed M. Chehimi, ${ }^{d, *}$ Changseok Han, ${ }^{\text {eff }}$ Ahmed A. Mohamed ${ }^{\mathrm{a}, *}$
}

a. Department of Chemistry, College of Sciences, University of Sharjah, Sharjah 27272, UAE

b. Center for Advanced Materials Research, Research Institute of Sciences and Engineering, University of Sharjah, Sharjah 27272, UAE

c. Polymer Institute, Slovak Academy of Sciences, Dúbravská cesta 9, 84541 Bratislava, Slovakia

d. Univ Paris Est Creteil, CNRS, ICMPE, UMR7182, F-94320 Thiais, France

e. Department of Environmental Engineering, INHA University, Korea 22212

f. Program in Environmental \& Polymer Engineering, Graduate School, INHA University, Korea 22212

Javad Parambath 0000-0002-5069-2143 (jbasil@sharjah.ac.ae)

Najrul Hussain 0000-0002-0612-7788 (najrul.hus sain@sharjah.ac.ae)

Mahreen Arooj 0000-0003-1975-5289 (marooj@sharjah.ac.ae)

Maria Omastova 0000-0003-0210-5861 (maria.omastova@savba.sk)

Mohamed Chehimi 0000-0002-6098-983X (chehimi@glvt-cnrs.fr)

Changseok Han 0000-0002-8636-2859 (hanck@ inha.ac.kr)

Ahmed Mohamed 0000-0001-7369-3117 (ah.mohamed@sharjah.ac.ae)

Corresponding Authors:

Ahmed A. Mohamed, PhD, ah.mohamed@sharjah.ac.ae

Mohamed M. Chehimi, PhD, chehimi@ icmpe.cnrs.fr 


\begin{abstract}
Graphene oxide (GO) was decorated with gold-aryl (Au-C) nanoparticles AuNPs-COOH by sodium borohydride reduction of aryldiazonium tetrachloroaurate(III) salt at room temperature in aqueous solutions. BET (Brunauer-Emmett-Teller) measurements supported the anchoring of GO by AuNPs modified with carboxyl functional groups; surface area dropped significantly. Morphology of AuNPs-COOH/GO nanocomposite (NC) was probed using AFM and TEM and images showed surface roughness and wrinkling. Molecular dynamics (MD) calculations endowed support of favorable wrinkling at the edges and carboxyl intercalation to GO surface of types $\pi-\pi$, hydrogen bonding, and hydrophobic interactions. Solvent accessible surface area calculations (SASA) of GO showed a decrease in total surface area, in agreement with BET results. Environmental nanoremediation of the catalytic reduction of nitrophenol and the electrocatalytic reduction of $\mathrm{CO}_{2}$ (model pollutants) were investigated. The apparent rate constants $\mathrm{K}_{\mathrm{app}}$ of the four catalytic reduction cycles of nitrophenol were measured. The highest value is $1.17 \times 10^{-1} \mathrm{~min}^{-1}$ for the first cycle which decreased to $4.49 \times 10^{-2} \mathrm{~min}^{-1}$ for the fourth cycle. Electrocatalytic studies revealed that the $\mathrm{NC}$ enhanced the $\mathrm{CO}_{2}$ reduction. The $\mathrm{NC}$ exhibited higher current densities in the $\mathrm{CO}_{2}$ solution saturated $\left(48 \mathrm{~mA} / \mathrm{cm}^{2}\right)$ compared to $\mathrm{N}_{2}(37$ $\mathrm{mA} / \mathrm{cm}^{2}$ ), indicating its superior catalytic activity in $\mathrm{CO}_{2}$ reduction.
\end{abstract}

Keywords: Graphene oxide, gold-aryl nanoparticles, nitrophenol reduction, carbon dioxide reduction, electrocatalytic, molecular dynamics calculations. 


\section{INTRODUCTION}

Gold nanocomposites (NCs) of graphene oxide (GO) platforms emerged as the foremost functional materials for applications in energy, environmental, and medical due to their unique electrical, physicochemical, and mechanical properties. ${ }^{1}$ For example, GO layers or NCs function as platforms for surface enhanced Raman spectroscopy studies. ${ }^{2}$ AuNPs/GO NCs are applied as electrochemical sensors and catalysts. ${ }^{3-5}$ The major advantages of GO are the low cost, water dispersibility, and the facile tunability of the physicochemical properties. However, conventional methods to synthesize and integrate graphene derivatives into functional materials are either hazardous or time and energy consuming. ${ }^{6-8}$ It is notable that the synthesis methods of GO decorated with NPs utilize high temperature, ultrasonication, and stirring for a prolonged period.

Recent progress is focused on the synthesis of functionalized GO with organic molecules ${ }^{9,10}$ and AuNPs ${ }^{11}$ to extend its applications in electrochemistry, ${ }^{12}$ catalysis, ${ }^{13}$ and bioanalytics. ${ }^{14}$ There are different approaches to fabricate AuNPs/GO NCs. Generally, chemical reducing agents such as sodium citrate, ${ }^{15}$ sodium borohydride ${ }^{16}$ and biodegradable reducing agents such as tyrosine $e^{5}$ are utilized to reduce $\mathrm{HAuCl}_{4}$ to AuNPs. These NPs are either chemically or mechanically adhered to GO layers.

The organic derivative 4-aminophenol (4- $\mathrm{APh})$ is an important agent for preparing drugs, corrosion inhibitors and lubricants. ${ }^{17}$ It can be synthesized by simple catalytic reduction of the environmental pollutant 4-nitrophenol (4-NPh) using $\mathrm{NaBH}_{4}$ and noble metal NPs catalysts. The reduction of 4-NPh using $\mathrm{NaBH}_{4}$ is commonly used as a model for evaluating the catalytic performance of metal NPs. ${ }^{18}$ The thermodynamically feasible reaction can be brought in a suitable time frame by reducing the activation energy in presence of metal NPs catalysts.

Previously, a few studies reported the catalytic efficiency of AuNPs-graphene NCs in 4$\mathrm{NPh}$ reduction using $\mathrm{NaBH}_{4}$. Zhang et al. studied the activity using porous AuNPs/GO/polyethyleneimine NCs. ${ }^{19}$ Choi et al. reported one pot synthesis of AuNPs/GO NC as two-dimensional sheets in which the AuNPs are well exposed for the catalytic activity. ${ }^{20}$ Further, the synergistic effects and possibilities of fabricating AuNPs with GO were demonstrated.

Electrocatalytic $\mathrm{CO}_{2}$ reduction is a sustainable approach towards environmental remediation and its conversion to beneficial hydrocarbons. Thus, simultaneous environmental 
remediation and chemical conversions are challenging. It is critical to design catalysts to lower the $\mathrm{CO}_{2}$ reduction overpotentials and to find lower energy pathways. ${ }^{21}$ Recent advances in the synthesis of AuNPs allow physicochemical controlled highly selective $\mathrm{CO}_{2}$ reduction to $\mathrm{CO}{ }^{22}$ Monodispersed AuNPs with specific sizes were synthesized and studied in the electrocatalytic reduction of $\mathrm{CO}_{2}$ to $\mathrm{CO}$. Among all, the $8 \mathrm{~nm}$ AuNPs showed the highest selectivity, and their DFT calculations suggested highly selective $\mathrm{CO}$ formation due to the optimum ratio of the edges over the corner sites. $^{23}$

Efforts to prevent catalyst deactivation have called attention to the role of the supporting materials. $^{24-26}$ GO has gained significant interest because of its distinct morphology and electronic properties, which facilitate its strong $d-\pi$ interaction with metal NPs. ${ }^{27-29}$ Rogers et al. demonstrated enhanced electrocatalytic $\mathrm{CO}_{2}$ reduction with AuNPs/graphene nanoribbon NC. ${ }^{30}$ They revealed that the NC increased the AuNPs electrochemically active surface area, lowered the overpotential and increased the efficiency and stability. Recently, Nguyen et al. showed that tuning the electrocatalyst with GO dramatically varies the Faradaic efficiency (FE) for CO production from $\mathrm{CO}_{2}$ where GO layers play a major role in mass transport control. ${ }^{31}$

Recently, our group demonstrated the utilization of bentonite clay modified with aryldiazonium gold salts in the electrocatalytic hydrogen production in hydrogen evolution reaction (HER). ${ }^{32}$ Aryldiazonium gold(III) salts with perfluorinated chain $\left(\mathrm{C}_{8} \mathrm{~F}_{17}\right)$ were used to alter bentonite surface by the chemical reduction to form gold-aryl/clay NC. This gold-aryl catalyst paved efficient and stable electrochemical performance for the sustainable energy sector. We utilized the highly robust and water-soluble gold-aryl $\mathrm{NPs}$ for $\mathrm{NaBH}_{4}$ reduction of $4-\mathrm{NPh}^{33}$

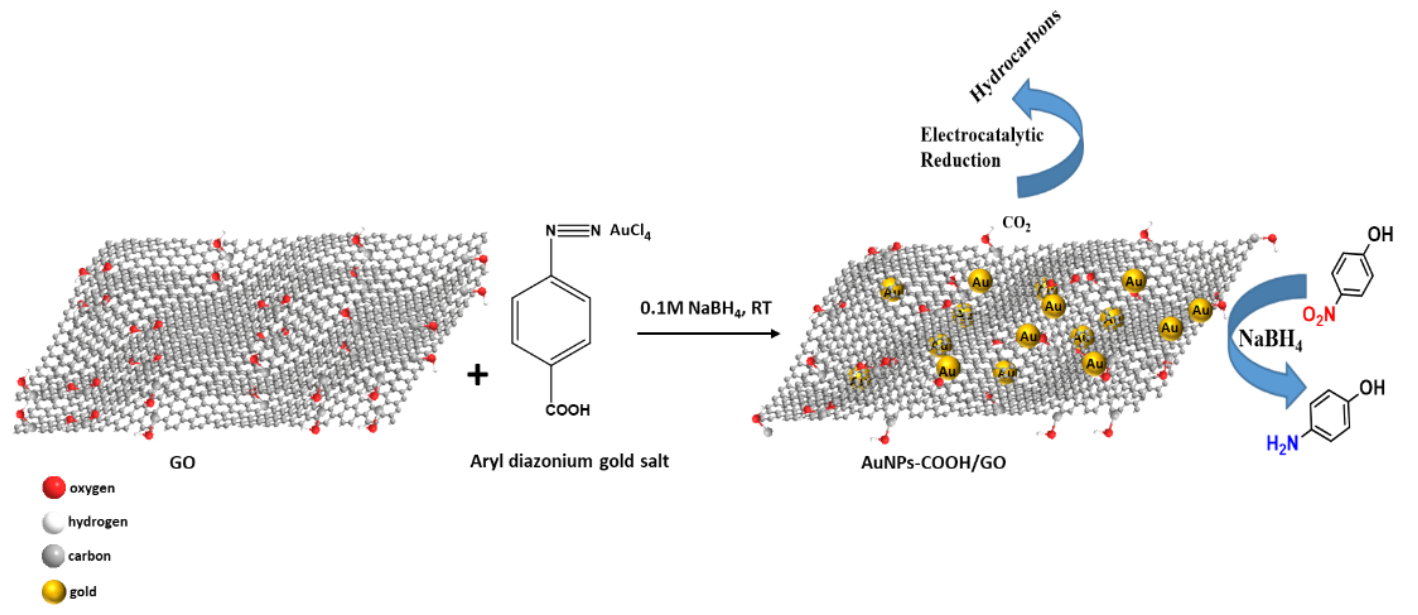

Figure 1. AuNPs-COOH/GO NC preparation. 
Oxygen functionalities such as epoxide and hydroxyl on GO layers endow sites for surface modified AuNPs with 4-carboxyphenyl functional groups via aryldiazonium route (Figure 1). Here we describe the bottom-up design of AuNPs-COOH/GO for the catalytic reduction of $4-\mathrm{NPh}$ by $\mathrm{NaBH}_{4}$ along with enhancing the performance parameters of the electrocatalytic reduction of $\mathrm{CO}_{2}$. Molecular dynamics (MD) calculations were used to study the various types of interactions of the carboxyl functional groups with GO layers. We aimed to probe the interaction sites on GO, i.e. wrinkle versus edge adsorption. To the best of our knowledge, this is the first time to reduce aryldiazonium salt of tetrachloroaurate(III) to prepare gold-aryl NPs/GO (hereinafter referred to as $N C$ ).

\section{EXPERIMENTAL SECTION}

Materials. Chemical compounds, 4-aminobenzoic acid (99.1\%, Chem Impex), 4-aminophenol (98\%, Alfa Aesar), graphite powder (Sigma-Aldrich), sodium borohydride (Fisher Chemicals), 4-nitrophenol (99\%, Acros Organics), potassium bicarbonate (LR grade, Merk), potassium permanganate (Sigma-Aldrich), sulfuric acid (SDFCL, AR grade), hydrogen peroxide (Merk, $30 \%$ ), potassium cyanide (Sigma-Aldrich), hydrochloric acid (SDFCL, AR grade), isopropanol (ACS grade, SDFCL) D521 Nafion ${ }^{\circledR}$ dispersion and all solvents were reagent grade and used without further purification.

Characterization. UV-vis absorption spectra were measured using Spectro UV-2510TS, Labomed Inc. in the $200-800 \mathrm{~nm}$ range with $2 \mathrm{~nm}$ resolution.

Attenuated total reflectance Fourier transform infrared (ATR-FTIR) spectra were recorded on a Bruker (Platinum ATR) Tensor II FT-IR spectrophotometer.

X-ray powder diffraction (XRD) data were collected using Bruker D8 ADVANCE diffractometer with $\mathrm{Cu}-\mathrm{K} \alpha \mathrm{X}$-ray source at $\lambda=1.5406 \AA$ operating at $40 \mathrm{kV}$ tube voltage and $40 \mathrm{~mA}$ current.

Energy dispersive X-ray spectroscopy (EDS) analyses were performed with map and point modes at $50 \mathrm{kV}$ and $20 \mathrm{~mA}$.

XPS spectra were recorded using a K Alpha (Thermo) fitted with a monochromatic X-ray beam (radiation: $\mathrm{Al} \mathrm{K \alpha}, \mathrm{h} v=1486.6 \mathrm{eV}$, spot size $=400 \mu \mathrm{m}$ ). The pass energy was set to 200 and $50 \mathrm{eV}$ 
for the survey and the narrow regions, respectively. Electron and argon flood guns were used to compensate for the static charge buildup.

Thermal stability studies in the solid state were recorded in air using Shimadzu TGA analyzer at a scan rate of $20^{\circ} \mathrm{C} / \mathrm{min}$ in the temperature range $25-650{ }^{\circ} \mathrm{C}$ in platinum pans.

A Renishaw Ramascope was used for Raman measurements of solid samples. All Raman measurements were collected at laser excitation wavelengths of 785 and $514 \mathrm{~nm}$ in the scale range $200-3000 \mathrm{~cm}^{-1}$.

Cyclic voltammetry measurements were carried using VersaStat 4, USA, potentiostat.

Dynamic light scattering (DLS) measurements and $\zeta$-potential analyses of the nanoparticles in water were carried out using Anton Paar Litesizer 500 and analyzed using Kalliope ${ }^{\mathrm{TM}}$ software. TEM A JEOL JEM-2100 transmission electron microscope (TEM) was used for the morphology analysis. Dispersed NPs in acetonitrile were sonicated for 5 min using an ultrasonic cleaner (CPX2800HE, Branson Ultrasonics Corp., Connecticut, USA) and then immobilized on 300 mesh copper grids coated with LACEY carbon film (LC325-Cu, Electron Microscopy Sciences, Hatfield, Pennsylvania, USA).

Surface topography and roughness of the AuNPs-COOH and AuNPs-COOH/GO were analyzed using atomic force microscopy (AFM). Scanning measurements were carried out with a Flex-Axiom AFM (Nanosurf AG, Liestal, Switzerland) at a scan rate of $1 \mathrm{~Hz}$. Silicon cantilever with a reflective coating of aluminum (TAP150ALG, Budget Sensors, Sofia, Bulgaria) was used with a length of $125 \mu \mathrm{m}$, a resonant frequency of $150 \mathrm{kHz}$, and a force constant of $5 \mathrm{~N} / \mathrm{m}$. Data were analyzed using Nanosrf C3000 software. Briefly, $50 \mu \mathrm{L}$ of aqueous samples were coated on silicon wafer (100) by drop casting and drying for $24 \mathrm{~h}$ at room temperature. After blowing off the solution using nitrogen gas, the samples were probed using tapping mode AFM.

Synthesis of aryldiazonium tetrachloroaurate(III) salt. Aryldiazonium gold(III) salt [HOOC$\left.4-\mathrm{C}_{6} \mathrm{H}_{4} \mathrm{~N}^{+} \equiv \mathrm{N}\right] \mathrm{AuCl}_{4}$ was synthesized following our previously published procedure. ${ }^{33}$ A weight

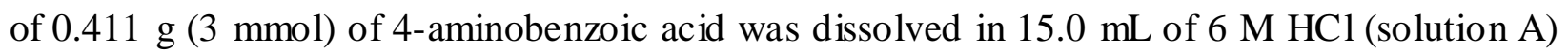
and a weight of $0.311 \mathrm{~g}(4.50 \mathrm{mmol}) \mathrm{NaNO}_{2}$ was dissolved in $5.0 \mathrm{~mL}$ of DI water (Solution B). Both solutions were brought to $0.0-5.0{ }^{\circ} \mathrm{C}$. Solution B was added dropwise to solution A while maintaining the same temperature range under continuous stirring for $1 \mathrm{~h}$. A weight of $1.182 \mathrm{~g}$ (3 mmol) of $\mathrm{HAuCl}_{4} \cdot 3 \mathrm{H}_{2} \mathrm{O}$ was dissolved in $10.0 \mathrm{~mL}$ of DI water and added slowly to the in situ formed aryldiazonium salt solution under vigorous stirring in an ice bath. A canary yellow 
precipitate was formed slowly and filtered. The solid was further washed with $10.0 \mathrm{~mL}$ of cold DI water, dried, and stored in the refrigerator for further use.

Synthesis of graphene oxide (GO). GO was prepared using a modified Hummers procedure. ${ }^{34}$ In this method, $2.0 \mathrm{~g}$ of graphite powder was added to $46 \mathrm{~mL}$ of $\mathrm{H}_{2} \mathrm{SO}_{4}$ and stirred in an ice bath for $1 \mathrm{~h}$ at temperature below $5^{\circ} \mathrm{C}$. Then, $12.0 \mathrm{~g}$ of $\mathrm{KMnO}_{4}$ was slowly added to the mixture and $92 \mathrm{~mL}$ of DI water was added under vigorous stirring for $1 \mathrm{~h}$. To remove the excess $\mathrm{KMnO}_{4}$, $40 \mathrm{~mL}$ of $30 \% \mathrm{H}_{2} \mathrm{O}_{2}$ solution was added slowly and stirred for $10 \mathrm{~min}$ to reduce the residual $\mathrm{MnO}_{2}$. The mixture was further diluted with $460 \mathrm{~mL}$ of DI water and $5 \% \mathrm{HCl}$ was added under vigorous stirring for $15 \mathrm{~min}$. Then the as formed GO was centrifuged and washed three times with DI water until the washing solution reached $\mathrm{pH}$ 7. The clear supernatant solution was freeze-dried to obtain $\mathrm{GO}$.

Synthesis of AuNPs-COOH/GO. $2 \mathrm{mg}$ of GO was dissolved in $25 \mathrm{~mL}$ DI water and sonicated for $10 \mathrm{~min}$. Then, $48.8 \mathrm{mg}$ of aryldiazonium tetrachloroaurate(III) salt [HOOC- $\mathrm{C}_{6} \mathrm{H}_{4}-4$ $\mathrm{N} \equiv \mathrm{N}] \mathrm{AuCl}_{4}$ was added and stirred at room temperature. Dropwise addition of $100 \mathrm{mM} \mathrm{NaBH}_{4}$ turned the solution to brown-black and the resultant solution was centrifuged and washed with DI water to collect AuNPs-COOH/GO solid.

KCN experiment. $1.0 \mathrm{mg} \mathrm{KCN}$ was dissolved in $1.0 \mathrm{~mL}$ of DI water to prepare $0.015 \mathrm{M}$ stock solution of $\mathrm{KCN}$. $300 \mu \mathrm{L}$ from the stock solution was used. Cyanide solution was added to the cuvettes containing $2.0 \mathrm{~mL}$ DI water along with $300 \mu \mathrm{L}$ AuNPs.

Molecular dynamics (MD) simulations. To investigate the properties of GO and its intercalations with benzoic acid molecules, MD simulations were carried out with software package GROMACS 2019.2 and the GROMOS force field force parameter set 54A7. ${ }^{35,36}$ The structure of GO cannot be clearly defined as the oxygen content of GO is amorphous. ${ }^{37}$ Following the widely accepted Lerf-Klinowski structural model, GO layer contained randomly attached hydroxyl and epoxy groups to both sides of its basal plane. Carboxyl functional groups were also attached randomly to the carbon atoms on the edges of GO. The force field force parameter for both GO and benzoic acid were taken from Automated Topology Builder (ATB) webserver. $^{38}$ One GO layer was placed at the center of the simulation box solvated with 8118 water molecules. The simulation box with size $7.3 \mathrm{~nm}(\mathrm{x}), 7.0 \mathrm{~nm}(\mathrm{y}), 5.0 \mathrm{~nm}(\mathrm{z})$, contained a layer of GO and four benzoic acid molecules placed around randomly from all directions. 
Simulation box was solvated with explicit simple point charge (SPC) water model. ${ }^{39}$ Electrostatic interactions were treated with a cutoff of $1.2 \mathrm{~nm}$ using particle mesh Ewald (PME) method. ${ }^{40}$ SHAKE algorithm was used to constrain all bonds involving hydrogen. Periodic boundary conditions were applied in all directions. First, the system performed 100,000 steps of steepest descent with energy minimization. Then, to equilibrate the whole system, equilibration simulations of $5 \mathrm{~ns}$ were performed followed by production simulations of $100 \mathrm{~ns}$. Snapshots of the simulated system were saved as trajectory file at every $10 \mathrm{ps}$ for further analysis. The g_hbond analysis tool as implemented in GROMACS was utilized to measure the total number of intermolecular hydrogen bonds (HB) formed between GO and benzoic acid molecules during the simulation time of 100 ns. In addition, g_sasa module in GROMACS was utilized to calculate the solvent accessibility surface area (SASA) of the simulated system.

Cataly tic reduction of 4-Nitrophenol (4-NPh). Reduction studies of 4-NPh were performed using a PerkinElmer Lambda $25 \mathrm{UV}$-vis spectrophotometer. A $0.02 \mathrm{~mL}$ of $0.01 \mathrm{M} 4-\mathrm{NPh}, 0.60$ $\mathrm{mL}$ of $100 \mathrm{mM} \mathrm{NaBH}_{4}$ and $0.88 \mathrm{~mL}$ of DI water were mixed in a $4.0 \mathrm{~mL}$ quartz cuvette. UV-vis spectra were recorded soon after the addition of $\mathrm{NC}$ catalyst. The reaction was monitored by the decrease in absorbance of 4-nitrophenolate at $400 \mathrm{~nm}$ with time.

Electrocatalytic reduction of $\mathrm{CO}_{2}$ reduction. Electrochemical performance of $\mathrm{NC}$ electrocatalyst towards $\mathrm{CO}_{2}$ reduction was investigated using three-electrodes cell (glassy carbon working electrode, $\mathrm{Pt}$ foil counter electrode, and $\mathrm{Ag} / \mathrm{AgCl}$ reference electrode). NC was dispersed in a mixture of Nafion and isopropanol solution using ultrasonication, then a desired volume of the dispersion was deposited on glassy carbon electrode and dried in the oven at $50{ }^{\circ} \mathrm{C}$ for $4 \mathrm{~h}$. Cyclic voltammetry measurements were performed using VersaStat 4, USA potentiostat in $0.5 \mathrm{M} \mathrm{KHCO}_{3}$ in water supporting electrolyte. Scan rate of $400 \mathrm{mVs}^{-1}$ was used in the potential range 0 to $-2 \mathrm{~V}$ vs. $\mathrm{Ag} / \mathrm{AgCl}$.

\section{RESULTS AND DISCUSSION}

Synthesis and solution studies. AuNPs-COOH/GO NC was prepared by $100 \mathrm{mM} \mathrm{NaBH}$ reduction of $\left[\mathrm{HOOC}-4-\mathrm{C}_{6} \mathrm{H}_{4} \mathrm{~N}_{2}\right] \mathrm{AuCl}_{4}$ in presence of $\mathrm{GO}$ at room temperature (Figure 1). The resulting colors were slightly different from the native AuNPs and NCs could be dispersed well 
in water. Nevertheless, we could observe some black powder after aging for two days, however, could be redispersed by gentle shaking.

UV-vis spectra (Figure 2A-B) showed the presence of a broad plasmon peak indicating large size NC formation. The native AuNPs-COOH showed the plasmon peak at $560 \mathrm{~nm}^{41}$ and size of $68 \mathrm{~nm},{ }^{33}$ and here with the modification with GO the size increased and the plasmon peak broadened. The NC exhibited a broad absorption peak in the range 550-580 nm. In addition, displayed a peak at $232 \mathrm{~nm}\left(\pi-\pi^{*}\right)$ assigned to $C=C$ bonds and a shoulder at $302 \mathrm{~nm}\left(\mathrm{n}-\pi^{*}\right)$ assigned to oxygen substituents.

Surface charges of the materials were probed using zeta potential ( $\zeta$-potential). Generally, $\zeta$-potential in the range -30 to $+30 \mathrm{mV}$ is indicative of a stable material due to electrostatic repulsion. The measured $\zeta$-potential of $\mathrm{GO}$ in water was $-46.8 \mathrm{mV}$, arising generally from the oxygen functionalities. Data showed that AuNPs-COOH and $\mathrm{NC}$ have $\zeta$ potential of $-28.68 \mathrm{mV}$ and $-28.73 \mathrm{mV}$ and average hydrodynamic size of $20 \mathrm{~nm}$ and $100 \mathrm{~nm}$, respectively. 

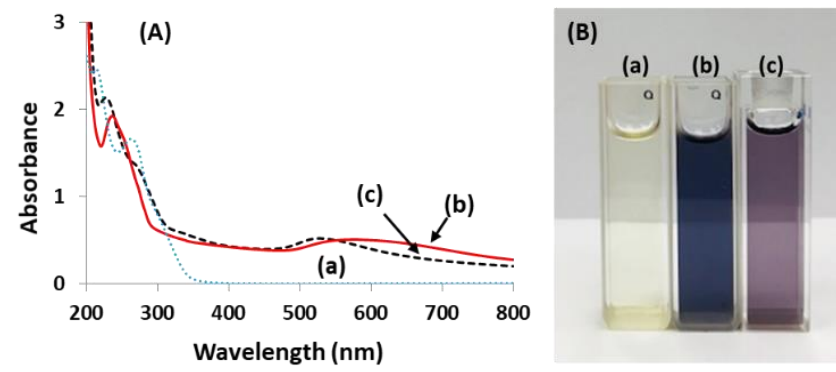

(C)
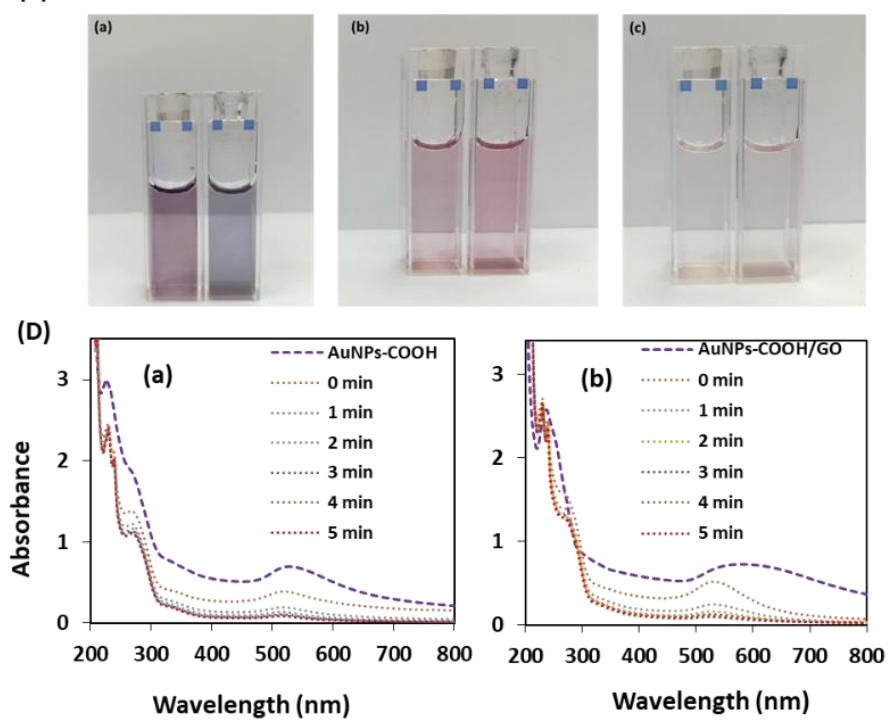

Figure 2. (A) UV-vis spectra of (a) $\left[\mathrm{HOOC}-4-\mathrm{C}_{6} \mathrm{H}_{4} \mathrm{~N}^{+} \equiv \mathrm{N}\right] \mathrm{AuCl}_{4}$ (blue small dots) (b) $\mathrm{NC}$ (red solid line), and (c) AuNPs-COOH (black broken line). (B) images of same materials, respectively. (C) $1.7 \mathrm{mM} \mathrm{KCN}$ study on AuNPs-COOH (left cuvette) and NC (right cuvette) (a) before KCN addition (b) just added KCN (0 min), and (c) after 5 min. (D) UV-vis study of (a) AuNPs- $\mathrm{COOH}$ and (b) NC after $\mathrm{KCN}$ addition.

Passivation of the gold core by instilled organic shell and further coating with GO was studied using $1.7 \mathrm{mM} \mathrm{KCN}$ on the native AuNPs and their NC (Figure 2C-D). It was observed that UV-vis plasmon peak of NC blue shifted from $550-580 \mathrm{~nm}$ to $520 \mathrm{~nm}$ followed by the disappearance in five minutes. Cyanide attack leached gold and further oxidized to $[\mathrm{Au}(\mathrm{CN})]^{-}$ associated with the color disappearance. The high dispersibility of NC in water could be the reason for the fast-oxidative dissolution of the gold core. UV-vis spectra after complete disappearance of plasmon peaks showed the characteristic peaks at 230 and $240 \mathrm{~nm}$ for $\left[\mathrm{Au}(\mathrm{CN})_{2}\right]^{-42}$ 
Solid state characterization. Raman spectroscopy revealed a band characteristic of Au-C stretch at $412 \mathrm{~cm}^{-1}$, a direct evidence of covalent bonding. ${ }^{43}$ The NC showed the presence of $v_{\mathrm{C}=\mathrm{C}}$ at $1584 \mathrm{~cm}^{-1}, \mathrm{C}-\mathrm{C}$ at $1333 \mathrm{~cm}^{-1}, v_{\mathrm{CCC}}$ at $1080 \mathrm{~cm}^{-1}$, and $\delta \mathrm{COO}^{-}$at $850 \mathrm{~cm}^{-1}$. Moreover, the diazonium peak disappearance at $2270 \mathrm{~cm}^{-1}$ supports the complete reduction of the salt.

Raman spectra of the NC (Figure 3a-d) showed two characteristic peaks at 1324 and 1599 $\mathrm{cm}^{-1}$ attributed to the intensity ratio of diamondoid (D)/graphitic (G) bands. Raman spectroscopy was used to probe possible structural changes of the GO layers during the $\mathrm{NaBH}_{4}$ reduction of the diazonium salt. Raman spectra of GO and NC displayed D band at $1342 \mathrm{~cm}^{-1}$ and $\mathrm{G}$ band at $1599 \mathrm{~cm}^{-1}$ assigned to bond stretching of $\mathrm{sp}^{2}$-hybridized carbon atoms. D band is associated with the presence of defects due to oxygen species such as hydroxyl or epoxide functional groups induced in plane $A_{1 g}$ zone-edge mode, however, the $G$ band is due to $E_{2 g}$ vibrational modes of $\mathrm{sp}^{2}$ orbitals. The ratio of the intensities of the $\mathrm{D}$ and $\mathrm{G}$ bands $\left(\mathrm{I}_{\mathrm{D}} / \mathrm{I}_{\mathrm{G}}\right)$ is often used to measure the degree of GO disorder. The $\mathrm{I}_{\mathrm{D}} / \mathrm{I}_{\mathrm{G}}$ ratio for our NC is 0.87 indicating a slight decrease in the size of the $\mathrm{sp}^{3}$ domains. Hence, the induced defect of GO layers is considerably very small during the $\mathrm{NaBH}_{4}$ reduction. Since no change was noticed in $\mathrm{I}_{\mathrm{D}} / \mathrm{I}_{\mathrm{G}}$, this indicates that the main domains of oxygenous groups in $\mathrm{GO}$ were unaltered after the diazonium salt reduction using high molarity of $100 \mathrm{mM} \mathrm{NaBH}$. This implies the consumption of the reducing agent mainly in the formation of AuNPs without GO functionalization. 

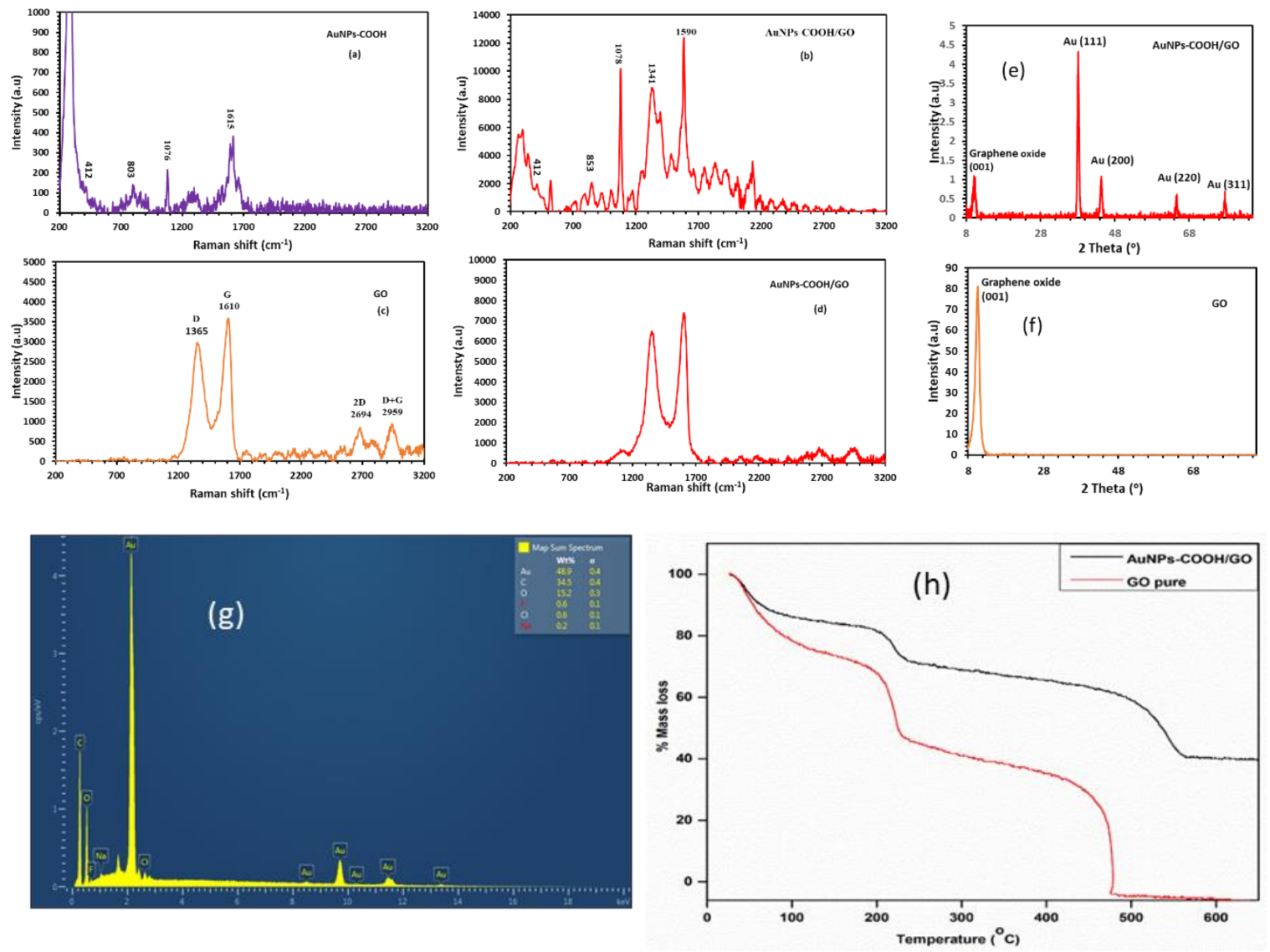

Figure 3. Raman spectra at $\lambda_{\text {ex }}=785 \mathrm{~nm}$ of (a) AuNPs-COOH (b) NC and Raman spectra at $\lambda_{\text {ex }}$ $=514 \mathrm{~nm}$ of (c) GO, and (d) NC. XRD pattern showing (e) NC (f) GO. TGA weight loss showing $\mathrm{NC}(\mathrm{g})$ and $\mathrm{GO}(\mathrm{h})$.

It is worth to comment on the possibility of diazonium functionalization by the addition reaction at $\mathrm{sp}^{2}$ carbon centers of GO. Diazonium salts have been reported as doping agents of graphene layers. The functionalization can occur by the reaction between the generated aryl radicals and GO layers. In GO, the free electrons are bound to oxygen-containing functionalities such as hydroxyl and epoxide groups. We probed the change in GO using Raman spectroscopy. The suspected covalent functionalization by diazonium is expected to significantly increase the intensity of integrated peak intensity of D peak. In our aryldiazonium gold(III) salt reduction and under the ambient conditions, we observed no change in $\mathrm{D}$ to $\mathrm{G}$ integrated peak intensity ratio $\left(\mathrm{I}_{\mathrm{D}} / \mathrm{I}_{\mathrm{G}}\right)$. In conclusion, the complete reduction of the aryldiazonium gold salt to gold-aryl NPs occurred without aryl functionalization of GO. 
Attenuated total reflectance Fourier transform infrared spectroscopy (ATR-FTIR) measurements of GO and NC showed the presence of strong and broad O-H stretching band at $3407 \mathrm{~cm}^{-1}$, carboxyl C=O at $1731 \mathrm{~cm}^{-1}, \mathrm{C}=\mathrm{C}$ at $1624 \mathrm{~cm}^{-1}, \mathrm{C}-\mathrm{OH}$ at $1400 \mathrm{~cm}^{-1}, \mathrm{C}-\mathrm{O}$ at $1089 \mathrm{~cm}^{-}$ 1 , and epoxy vibration in $\mathrm{GO}$ at $1225 \mathrm{~cm}^{-1}$.

The NC was further analyzed using powder X-ray diffraction (XRD) (Figure 3e-f). The observed broad diffraction peak at $\theta=9.55^{\circ}$ is assigned to (001) plane of GO in addition to the characteristic peaks for face centered cubic (fcc) AuNPs reflections (PDF Card \#4-784) at $2 \theta=38.1^{\circ}, 44.1^{\circ}, 64.5^{\circ}, 77.5^{\circ}$, and $81.5^{\circ}$. The low-angle diffraction is characteristic of an expanded GO interlayer spacing due to the oxygen containing functional groups and adsorbed water molecules. We calculated crystal grain size using Scherrer equation. We used the equation below to estimate the size of the crystalline gold D from XRD of the strong $\mathrm{Au}(111)$ diffraction peak,

$$
D=\frac{0.94 \cdot \lambda}{\beta \cdot \cos \theta}
$$

where $\lambda$ is the wavelength of the XRD source $(0.15406 \mathrm{~nm}), \beta$ is the line broadening at half the maximum intensity in radians, and $\theta$ is Bragg angle. From this analysis, we estimate that the mean crystalline size of the AuNPs is $24.4 \mathrm{~nm}$.

EDS showed $48.9 \%, 34.5 \%$, and $15.2 \%$ of $\mathrm{Au}, \mathrm{C}$, and $\mathrm{O}$, respectively (Figure $3 \mathrm{~g}$ ). TGA showed that GO started to lose weight upon heating but the main weight loss took place around $190{ }^{\circ} \mathrm{C}$ and lost $54 \%$ of the total weight due to pyrolysis of the labile oxygen containing functional groups. Remaining carbon layers were completely pyrolyzed after $445{ }^{\circ} \mathrm{C}$. Compared to GO, the thermal stability of $\mathrm{NC}$ is higher and showed a gradual weight loss in the entire temperature range (Figure 3h). The weight loss took place around $190{ }^{\circ} \mathrm{C}$ for the $\mathrm{NC}$ is only $11 \%$, which suggests that the thermal stability of the NC has been improved. In support to EDS, TGA also showed $42 \%$ gold after the complete pyrolysis. 

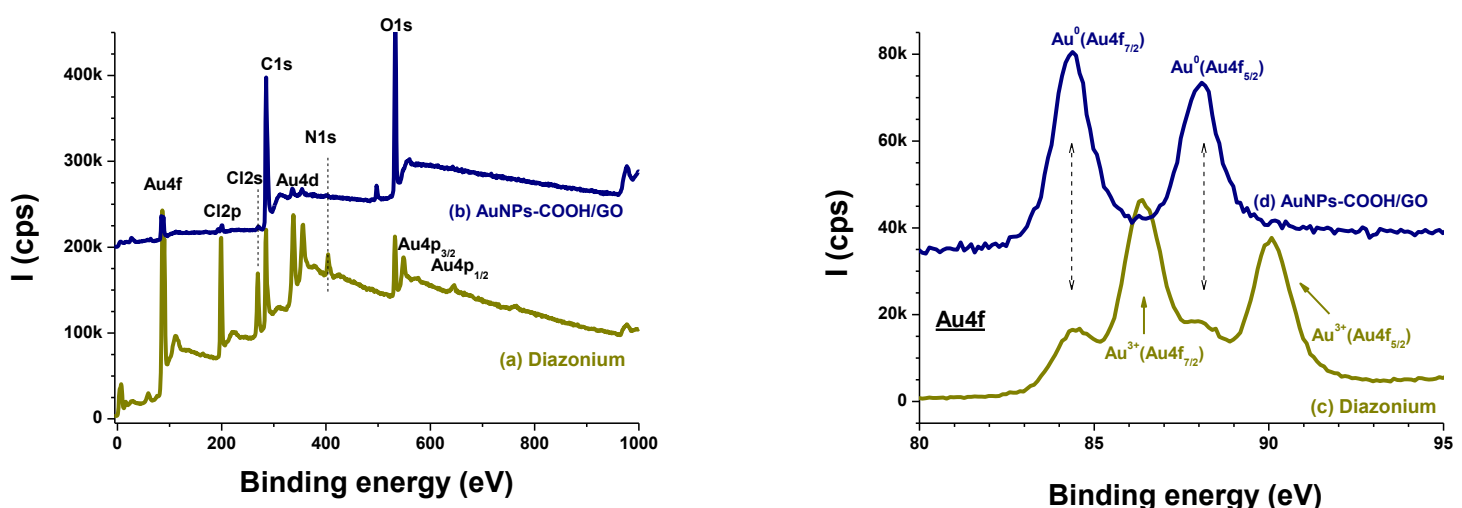

Binding energy (eV)
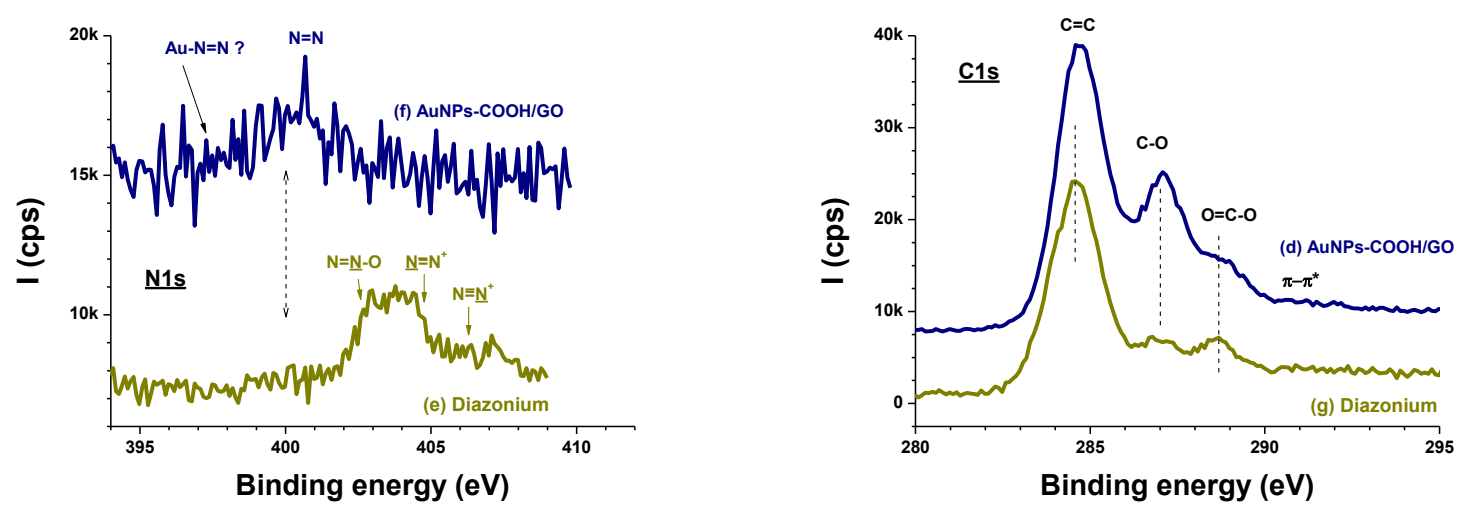

Figure 4. XPS survey regions $(\mathrm{a}, \mathrm{b})$; Au4f $(\mathrm{c}, \mathrm{d}), \mathrm{N} 1 \mathrm{~s}(\mathrm{e}, \mathrm{f})$ and $\mathrm{C} 1 \mathrm{~s}(\mathrm{~g}, \mathrm{~h})$ high resolution spectra of the $\left[\mathrm{HOOC}-4-\mathrm{C}_{6} \mathrm{H}_{4} \mathrm{~N}^{+} \equiv \mathrm{N}\right] \mathrm{AuCl}_{4}$ diazonium salt $(\mathrm{a}, \mathrm{c}, \mathrm{e}, \mathrm{g})$ and AuNPs-COOH/GO (b,d,f,h).

Survey regions (Figures 4a-b) clearly distinguish between the salt and the nanocomposite; the salt being dominated by gold core level peaks which are then attenuated due to the nanocomposite making. Nitrogen is hardly visible in the survey in Figure 4b, which accounts for the reductive reaction of the salt. This is similar for chlorine Cl2p and C2s peaks (Figure 4b). AuNPs-COOH/GO nanocomposite has prominent $\mathrm{C} 1 \mathrm{~s}$ and O1s peaks. Slight concave shape of the inelastic background in Figure 4b at high binding energy side of Au4f, C1s and O1s indicate that gold and GO attenuate each other, therefore supporting a layered intercalated structure. In Figures $4 \mathrm{c}-\mathrm{d}$, there is clear reductive reaction of $\mathrm{AuCl}_{4}{ }^{-}$anion into metallic gold in AuNPs$\mathrm{COOH} / \mathrm{GO}$ (Figure 4d). However, the salt itself undergoes partial reduction during XPS as the dominant $\mathrm{Au} 4 \mathrm{f}$ doublet corresponds to $\mathrm{Au}(\mathrm{III})$ oxidation state, but the metallic is definitely detected $\left(\mathrm{Au}_{4} \mathrm{f}_{7 / 2}\right.$ centred at $\sim 84 \mathrm{eV}$, see Figure $4 \mathrm{c}$ ). The $\mathrm{Au}(\mathrm{III}) / \mathrm{Au}^{0}$ atomic ratio is $\sim 2.85$. We have noticed such photoreduction for $\left[\mathrm{O}_{2} \mathrm{~N}-4-\mathrm{C}_{6} \mathrm{H}_{4} \mathrm{~N}^{+} \equiv \mathrm{N}\right] \mathrm{AuCl}_{4}$ diazonium salt. ${ }^{44}$ In situ, X-ray 
induced reduction is actually known fact, and discussed in several reports; it affects not only gold salts ${ }^{45}$ but also $\mathrm{PVC},{ }^{46}$ azides ${ }^{47}$ and $\mathrm{Cu}(\mathrm{II}),{ }^{48}$ to name but these compounds.

$\mathrm{NaBH}_{4}$-induced reaction is very clear in the case of the diazonium group (Figures $4 \mathrm{e}-\mathrm{f}$ ). It is interesting to note whole spectral structure shifting from high to low binding energy (BE) side on going from the salt (Figure 4e) to the nanocomposite (Figure 4f). Indeed, the rule of thumb is that for a given element high (low) oxidation state yields peak at high (low) BE position. Of particular interest is the complex structure of the diazonium N1s spectrum. The two N1s peaks from $-\mathrm{N}^{+} \equiv \mathrm{N}$ can be distinguished ${ }^{49}$ but obviously $\mathrm{X}$-ray induced reduction has certainly occurred. Indeed, Figure 4e shows component centred at $\sim 403 \mathrm{eV}$ which could be assigned to $\mathrm{N}=\underline{\mathrm{N}}-\mathrm{O}$. Indeed, it is possible that $-\mathrm{N}^{+} \equiv \mathrm{N}$ reacts with $\mathrm{COOH}$ from an adjacent cation, which results in interfacial bond in a dimer. Although very noisy, the signal at $\sim 400 \mathrm{eV}$ could be due $\mathrm{N}=\mathrm{N}$-. This component is dominant in the very noisy N1s feature from the AuNPs-COOH/GO nanocomposite. There is also possible formation of $-\mathrm{N}=\mathrm{N}-\mathrm{Au}$ interfacial bond as could be noticed from Figure 4f. Such an interface has been reported by the team of Guy Deniau. ${ }^{\mathbf{5 0}}$ Finally, Figure $4 \mathrm{~g}$ displays the $\mathrm{C} 1 \mathrm{~s}$ region of the salt with prominent $\mathrm{sp}^{2}$ carbon atoms from the benzene ring and a component at $288.7 \mathrm{eV}$ for the $\mathrm{COOH}$. The $\pi-\pi *$ shake-up satellite centred at $\sim 291 \mathrm{eV}$ testifies for the aromatic nature of the cation. The final peak at $\sim 287 \mathrm{eV}$ is assigned to $\mathrm{C}-\mathrm{O}$ bond, possibly an $\mathrm{X}$-ray induced esterification resulting from the reaction of two cations: $\mathrm{HOOC}-4-\mathrm{C}_{6} \mathrm{H}_{4} \mathrm{~N}^{+} \equiv \mathrm{N}+\mathrm{HOOC}-4-\mathrm{C}_{6} \mathrm{H}_{4} \mathrm{~N}^{+} \equiv \mathrm{N} \rightarrow \mathrm{HOOC}-4-\mathrm{C}_{6} \mathrm{H}_{4} \mathrm{~N}=\mathrm{N}-\mathrm{O}-\mathrm{C}(=\mathrm{O})-4-\mathrm{C}_{6} \mathrm{H}_{4} \mathrm{~N}^{+} \equiv \mathrm{N}$ $\rightarrow \mathrm{HOOC}-4-\mathrm{C}_{6} \mathrm{H}_{4}-\mathrm{O}-\mathrm{C}(=\mathrm{O})-4-\mathrm{C}_{6} \mathrm{H}_{4} \mathrm{~N}^{+} \equiv \mathrm{N}+\mathrm{N}_{2} \uparrow$.

In Figure 4h, The $\mathrm{C} 1 \mathrm{~s}$ is also complex and shows prominent $\mathrm{C} 1 \mathrm{~s}$ component assigned to $\mathrm{C}-\mathrm{O}$ which is in line with the oxidized state of carbon atoms in GO. Most probably the $\mathrm{COOH}$ feature accounts for a possible minor reaction of the diazonium with GO. The $\pi-\pi *$ shake-up satellite centred at $\sim 291 \mathrm{eV}$ is also in line with $\mathrm{sp}^{2}$ nature of graphitic carbon atoms of GO.

Surface area and pore size of GO and NC were measured using BET (Brunauer-EmmettTeller) methods. The nitrogen adsorption-desorption isotherms of GO and NC (Table 1, Figure 5a-d) at conditions of $77 \mathrm{~K}$ and 10 torr. By comparing the isotherms, the curve shows type VI of the IUPAC classification describing the adsorption behavior. At low relative pressure $\mathrm{P} / \mathrm{P}_{0}<0.5$, the isotherm showed the formation of monolayer, however, after the inflection point at $\mathrm{P} / \mathrm{P}_{0}=$ 0.5, the pores started filling and multilayer formation started. As the pressure increased, the NC 
showed a narrow hysteresis loop type $\mathrm{H} 4$ in the range $\mathrm{P} / \mathrm{P}_{0}=0.5-1.0$. The corresponding BET specific surface area of NC is $91.3 \mathrm{~m}^{2} / \mathrm{g}$ which is less than GO $\left(41.7 \mathrm{~m}^{2} / \mathrm{g}\right)$. Our results are supported by several literature examples where graphene derivatives display lower surface areas upon the formation of NCs.

BET surface area was calculated from the linear plot of the multipoint BET measurement. The low pore radius and the uptake at low $\mathrm{P} / \mathrm{P}_{0}$ of $\mathrm{H} 4$ loop indicates the presence of micropores in the adsorbent. Textural properties of GO and NC are given in Table 1. From the results, we can obviously observe that the surface area and pore volume of $\mathrm{NC}$ are less than $\mathrm{GO}$, indicating the interaction of the two entities.

\section{Table 1. BET Surface Area}

\begin{tabular}{|l|c|c|c|}
\hline Sample & $\mathrm{S}_{\mathrm{BET}}\left(\mathrm{m}^{2} \mathrm{~g}^{-1}\right)$ & BJH pore volume $\left(\mathrm{cm}^{5} \mathrm{~g}^{-1}\right)$ & BJH pore radius $(\mathrm{nm})$ \\
\hline $\mathrm{GO}$ & 91.3 & $7.4 \times 10^{-2}$ & 1.72 \\
\hline $\mathrm{NC}$ & 41.7 & $3.1 \times 10^{-2}$ & 1.94 \\
\hline
\end{tabular}
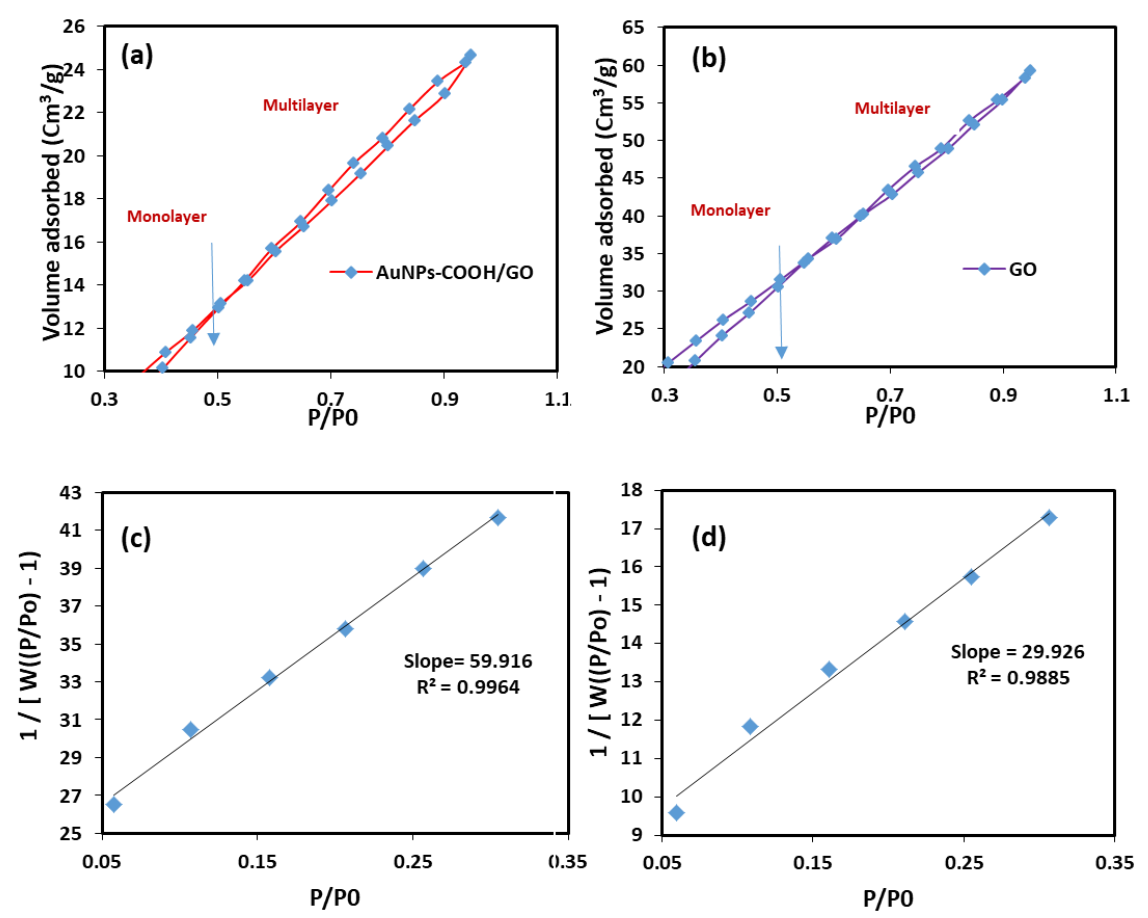

Figure 5. $\mathrm{N}_{2}$ adsorption-desorption isotherms for (a) NC (b) GO and BET plot of (c) NC and (d) $\mathrm{GO}$ collected at the relative pressure $\mathrm{P} / \mathrm{P}_{0}$ range $0.05-0.3$. Equations of the best-fit line and $\mathrm{R}^{2}$ values are shown on the graphs. 
Morphology of NC was investigated by AFM. Figure 6A-B shows AFM images of AuNPs-COOH and NC. The dispersion of AuNPs on the 2D sheet of GO can be visualized. The height profile of NC images indicates an increased height compared to the native AuNPs-COOH, which corresponds to the background height of GO layers. AFM analysis further confirmed our ability to achieve uniform distribution of AuNPs-COOH on micron scale GO sheets. Area roughness measured from AFM for AuNPs-COOH and $\mathrm{NC}$ are $2.48 \mathrm{~nm}$ and $8.14 \mathrm{~nm}$, respectively. Increased surface roughness indicates AuNPs-COOH are embedded into GO layers.

TEM analysis was performed to probe the structural morphology of the samples. As a result of TEM analysis, $8.9 \pm 3.4 \mathrm{~nm}$ of AuNPs-COOH was prepared and the measured lattice spacing of $0.204 \mathrm{~nm}$, corresponding to (200) plane of metallic gold in AuNPs-COOH. ${ }^{51}$ As shown in Figure 6C, spherical AuNPs-COOH were well incorporated in GO. The size of AuNPs$\mathrm{COOH}$ in the $\mathrm{NC}$ ranged from 4.7 to $37.4 \mathrm{~nm}$ and an averaged size was $12.8 \pm 7.6 \mathrm{~nm}$. GO in the NC looks very flat but wrinkled structures were found at several places but mainly located at the edges. Similar results were reported by Tang et al. in 2018 showing that aromatic compounds exhibit a strong preference in adsorbing near the wrinkles and edges. ${ }^{52}$ The measured lattice spacing of $0.235 \mathrm{~nm}$, corresponding to (111) plane of gold, ${ }^{53}$ confirmed the formation of AuNPs$\mathrm{COOH}$. The selected area electron diffraction (SAED) also confirms the formation of NC. SAED patterns clearly showed the presence of GO and AuNPs-COOH with diffraction patterns of GO and metallic gold. 

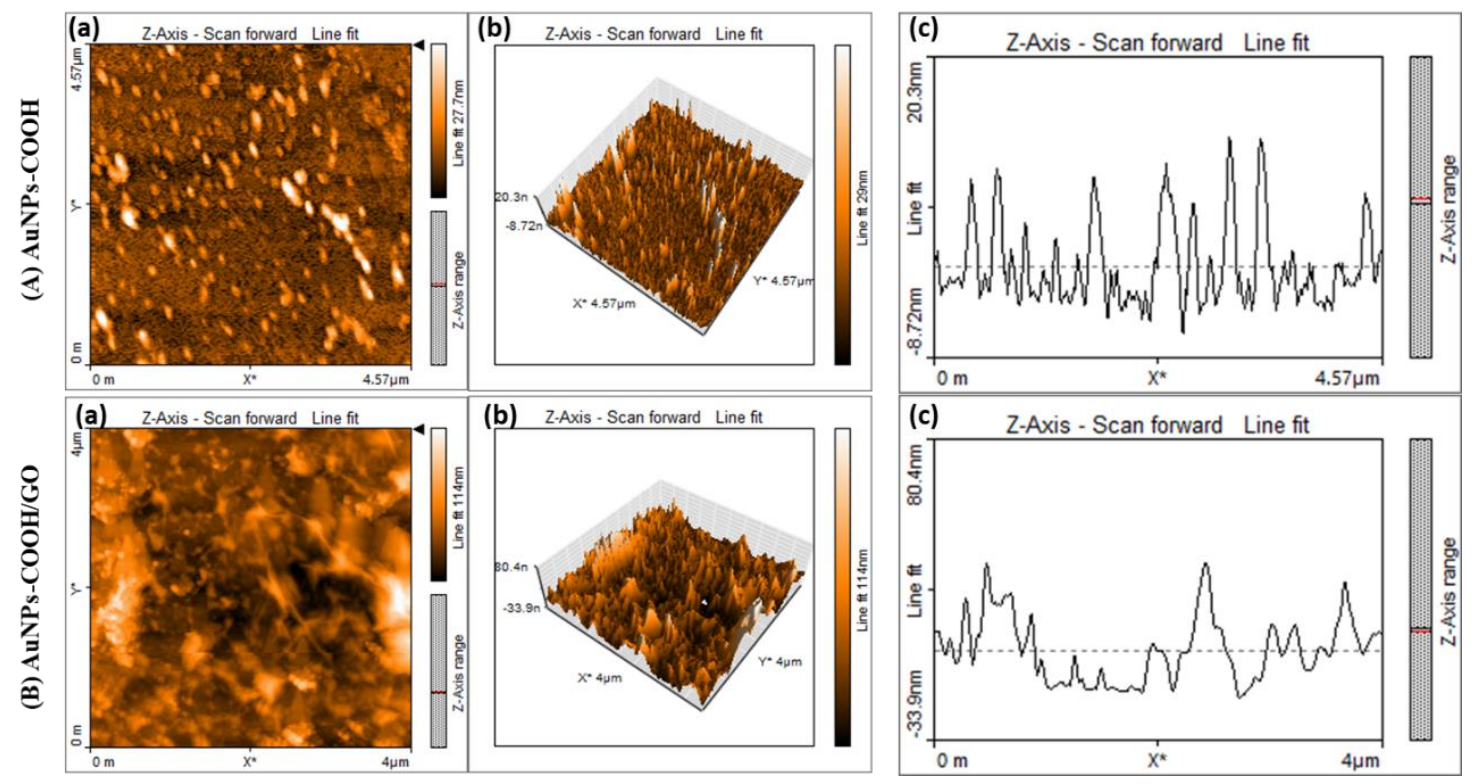

(C)
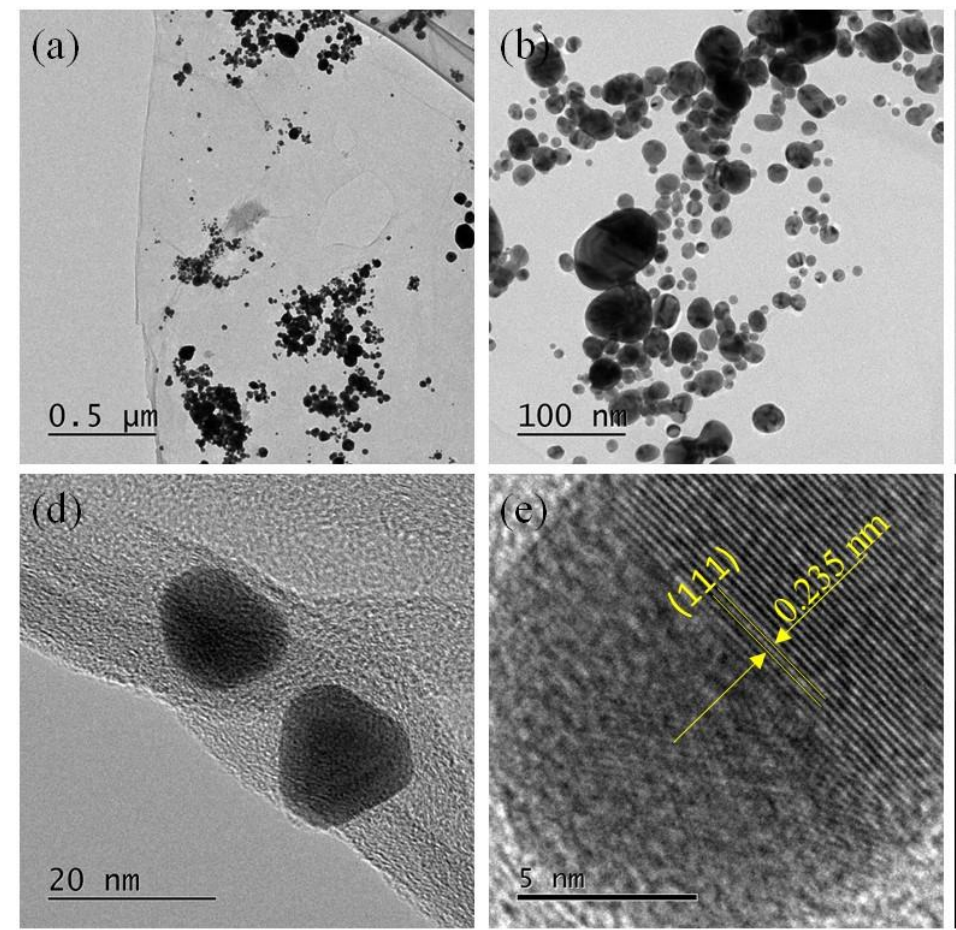

(c)
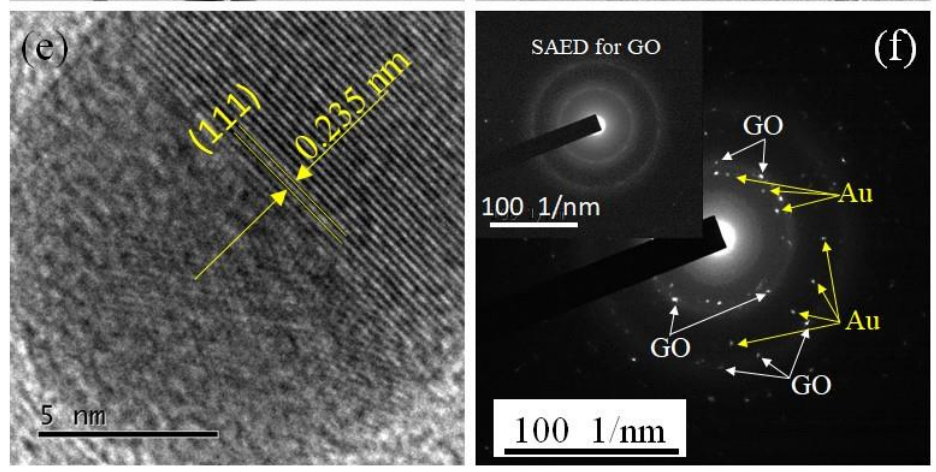

Figure 6. (A-B) AFM images of AuNPs-COOH and $\mathrm{NC}$ : (a) $2 \mathrm{D}$ image, (b) 3D image, and height profile. (C) TEM images (a)-(e) and SAED (f) NC (inserted image in (f) shows SAED patterns of $\mathrm{GO}$ ). 
Molecular dynamics simulations. Trajectory retrieved from the molecular dynamics simulations was used to evaluate the binding mode interactions of GO layer with benzoic acid. Hydrogen bonding analysis revealed that benzoic acid molecules were able to maintain various hydrogen bonding interactions with GO during the simulation time. Hydroxyl and carbonyl oxygen of benzoic acid formed strong hydrogen bonding interactions with hydroxyl and epoxy groups of GO, (Figure 7A-B). The strength of these hydrogen bond ing contacts with GO layer is evident from the short distances for hydrogen bonding interactions such as $1.67,1.74$, and 1.87 $\AA$. Further investigation of the conformations also revealed the presence of $\pi$ - $\pi$ stacking interactions between benzoic acid and GO. Thus, the conformation of benzoic acid-GO complex was highly stable because of $\pi-\pi$ stacking and hydrogen bonding interactions. Binding analysis of GO with cellulose, tri-alanine, and palmitic acid showed the presence of a few intermolecular hydrophobic interactions. ${ }^{54}$ Another study examined the adsorption of aromatic compounds on GO and showed the importance of $\pi-\pi$ stacking and hydrogen bonding interactions for putative binding. ${ }^{55}$

To appraise the surface behavior of GO layer during simulation, solvent accessible surface area (SASA) analysis was performed. The comparison between the surface area of GO before and after MD simulations showed a clear reduction in SASA values from $12.9 \mathrm{~nm}^{2}$ to $8.2 \mathrm{~nm}^{2}$. This reduction for GO may be due to the following two factors. The first one is explicit with GO layers wrinkling. The second could be due to the presence of benzoic acid molecules above and below the plane of GO layer. 


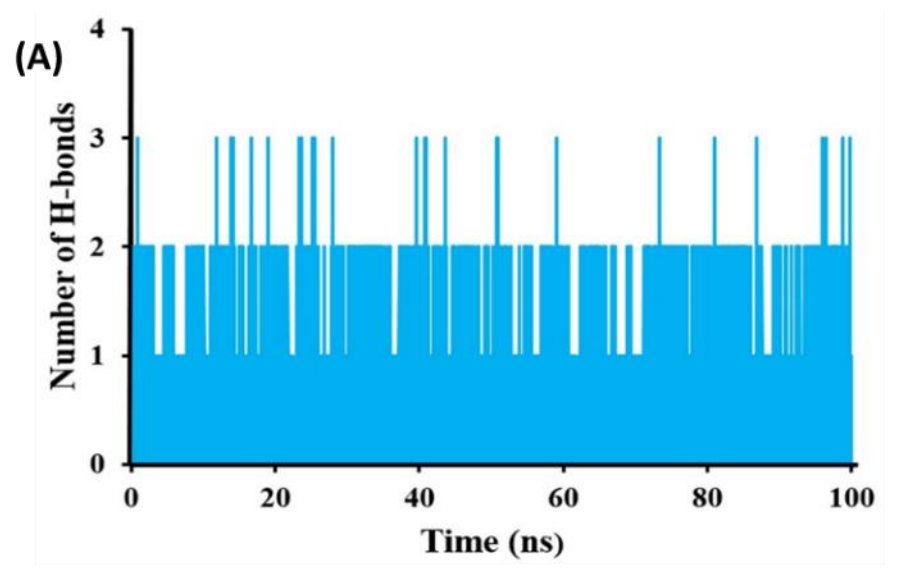

(B)

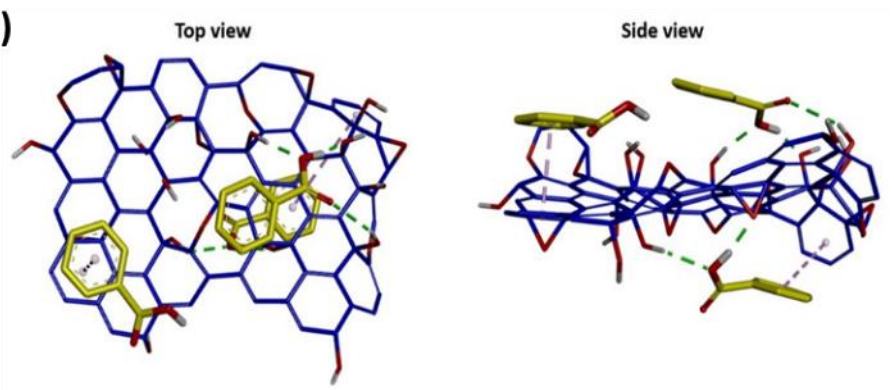

Figure 7. (A) Intermolecular hydrogen bonding interactions of benzoic acid with GO throughout the simulation time. (B) binding mode interactions between $\mathrm{GO}$ and benzoic acid. Hydrogen bonding and $\pi-\pi$ interactions are indicated using green and pink dashed lines, respectively. GO and benzoic acid molecules represented by blue and yellow stick style, respectively. Only polar hydrogen atoms are shown for clarity.

Cataly tic reduction of 4-NPh. The reduction reaction of 4-NPh proceeds in aqueous solution and can be easily monitored by following the disappearance of 4-nitrophenolate ion at $400 \mathrm{~nm}$ using UV-vis. On treatment with excess $\mathrm{NaBH}_{4}$, 4-NPh can cleanly convert to 4- $\mathrm{APh}$ and the reaction follows pseudo first-order kinetics. The apparent catalytic rate constant $\left(\mathrm{k}_{\mathrm{app}}\right)$ can be calculated from the decay of 4-nitrophenolate peak. ${ }^{56}$ Eley-Rideal or Langmuir-Hinshelwood $(\mathrm{L}-\mathrm{H})$ are the conceivable mechanisms which describe heterogeneous catalysis pathways for the adsorption of the reactants on the catalyst surface. In the Eley-Rideal model, only one of the reactants is adsorbed, ${ }^{57}$ whereas in Langmuir-Hinshelwood model both reactants are adsorbed. ${ }^{58}$ More often, $\mathrm{L}-\mathrm{H}$ mechanism is proposed in which both $\mathrm{BH}_{4}{ }^{-}$and $4-\mathrm{NPh}$ interact with catalyst surface, followed by reduction of $4-\mathrm{NPh}$ to $4-\mathrm{APh}$ and desorption. ${ }^{18}$ 
The catalytic effect of NC on the reduction of 4- $\mathrm{NPh}$ with $100 \mathrm{mM} \mathrm{NaBH} 4$ to form 4$\mathrm{APh}$ was examined. We observed an evolution of a new peak for $4-\mathrm{APh}$ at $300 \mathrm{~nm}$ concomitant with a decrease in the 4-NPh peak at $400 \mathrm{~nm}$ (Figure $8 \mathrm{a}-\mathrm{b}$ ). The peak at $400 \mathrm{~nm}$ diminished over prolonged reaction time of $16 \mathrm{~min}$. Also, there was no reaction when only GO was added, which indicates NC effectively functioned as a catalyst.
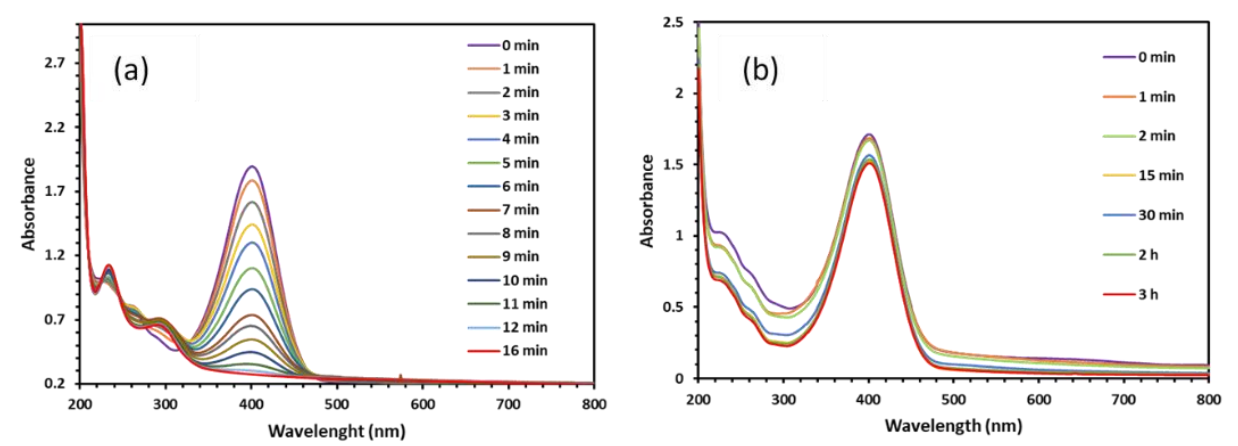

Figure 8. UV-vis spectra of 4- $\mathrm{NPh}$ reduction (a) 4-NPh with $\mathrm{NaBH}_{4}$ and the $\mathrm{NC}$ catalyst and (b) 4-NPh with $\mathrm{NaBH}_{4}$ and GO.
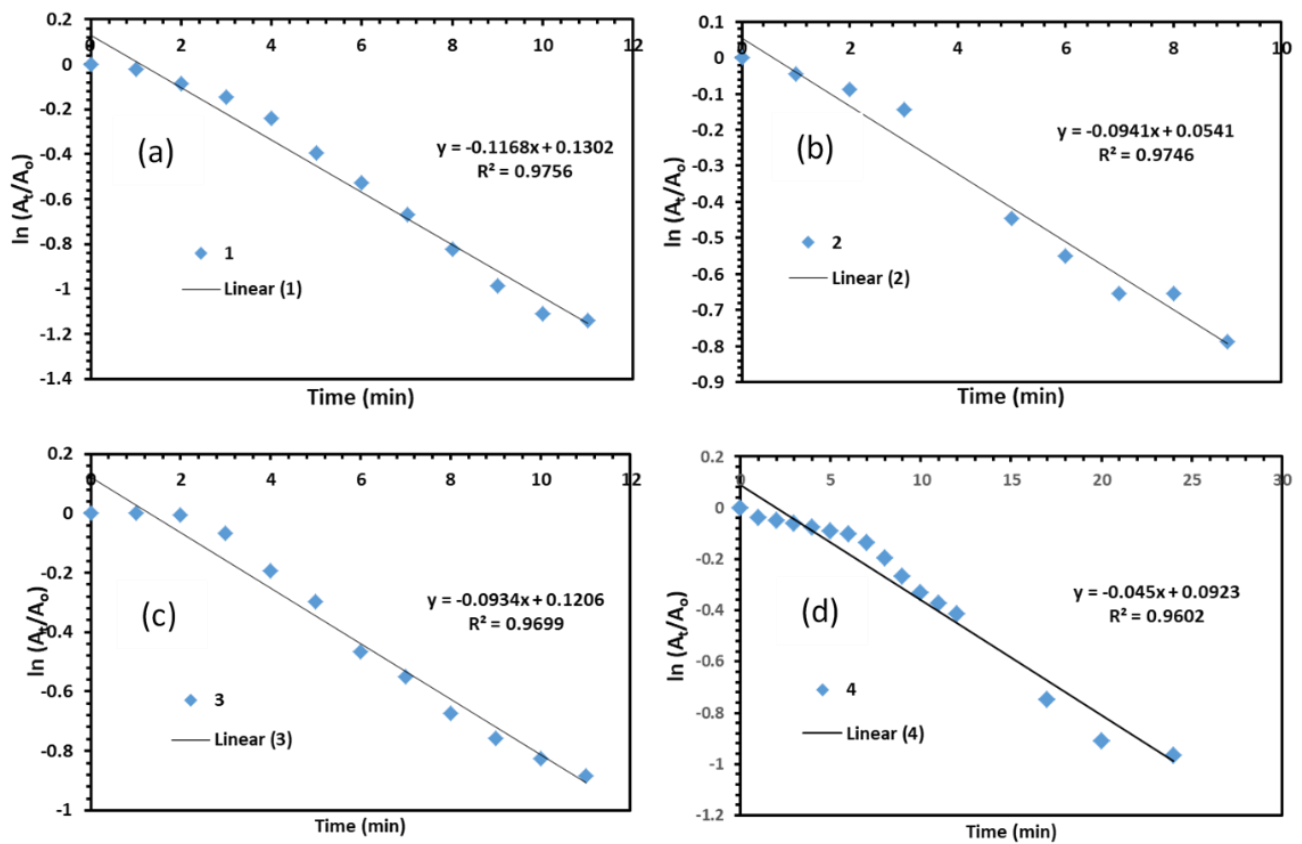

Figure 9. Plots of $\ln \left(A_{t} / A_{0}\right)$ vs. time for the reduction of 4-NPh. Shown the $\ln \left(A_{t} / A_{0}\right)$ vs. time for the four successive catalytic cycles. 
In this work, the reduction of $4-\mathrm{NPh}$ to $4-\mathrm{APh}$ is a pseudo first-order kinetics regarding 4$\mathrm{NPh}$ in presence of excess $\mathrm{NaBH}_{4}$ (Table 2, Figure 9a-d). Measuring the absorption peak of 4$\mathrm{NPh}$ at $400 \mathrm{~nm}$ with reaction time and plotting $\ln \left(\mathrm{A}_{\mathrm{o}} / \mathrm{A}_{\mathrm{t}}\right)$ vs. reaction time $(\mathrm{t})$, the apparent reaction rate constant $\left(\mathrm{k}_{\mathrm{app}}\right)$ was calculated. As shown in Figure 9a-d, a linear relationship between $\ln \left(A_{t} / A_{0}\right)$ and reaction time $(t)$ was obtained, indicating that the reaction is pseudo firstorder with respect to 4-NPh. The apparent rate constants were measured from the slope.

Table 2. Rate constants for Reduction of 4-NPh

\begin{tabular}{|l|c|}
\hline Catalyst & $\mathbf{K}_{\text {app }}\left(\mathbf{m i n}^{-1}\right)$ \\
\hline AuNPs-COOH/GO (1) & $1.17 \times 10^{-1}$ \\
\hline AuNPs-COOH/GO (2) & $9.41 \times 10^{-2}$ \\
\hline AuNPs-COOH/GO (3) & $9.34 \times 10^{-2}$ \\
\hline AuNPs-COOH/GO (4) & $4.49 \times 10^{-2}$ \\
\hline
\end{tabular}

Electrocatalytic reduction of $\mathrm{CO}_{2}$. The disturbing increase in $\mathrm{CO}_{2}$ emission is having a dramatic effect on global warming and climate change. To reduce the negative impacts of $\mathrm{CO}_{2}$ emission on climate change, it is critical to find solutions to utilize $\mathrm{CO}_{2}$ by converting to valueadded chemical products using renewable energy. ${ }^{59}$ Electrocatalytic $\mathrm{CO}_{2}$ reduction offers a sustainable approach towards the production of carbon-based $\mathrm{C} 1$ and $\mathrm{C} 2$ fuel products. ${ }^{60-62}$ Thus, electrocatalytic reduction of $\mathrm{CO}_{2}$ into carbon-containing chemicals is a sustainable technology to attenuate dispensable $\mathrm{CO}_{2}$. However, the reduction is a complex electron-transfer process, which leads to different products. ${ }^{63}$ Capturing $^{64}$ and conversion ${ }^{65}$ of $\mathrm{CO}_{2}$ to useful chemicals is the most plausible route to low-carbon economy. ${ }^{66}$ In this study we applied NC in the electrocatalytic reduction of $\mathrm{CO}_{2}$ and compared its promising advancement with $\mathrm{GO}$ and AuNPs-COOH.

Current density of the synthesized materials was determined using cyclic voltammetry in the potential range of 0 to $-0.2 \mathrm{~V}$ to evaluate their electrocatalytic performance towards $\mathrm{CO}_{2}$ reduction. Figure 10 displays cyclic voltammograms (CVs) of $\mathrm{NC}$ in $\mathrm{N}_{2}$ and $\mathrm{CO}_{2}$ saturated $0.5 \mathrm{M}$ $\mathrm{KHCO}_{3}$ solutions. It can be clearly seen from Figure 10 that $\mathrm{NC}$ exhibited higher current densities in $\mathrm{CO}_{2}\left(48 \mathrm{~mA} / \mathrm{cm}^{2}\right)$ compared to the solution saturated with $\mathrm{N}_{2}\left(37 \mathrm{~mA} / \mathrm{cm}^{2}\right)$. This result clearly confirmed $\mathrm{NC}$ role as a superior electrocatalyst in $\mathrm{CO}_{2}$ reduction. 

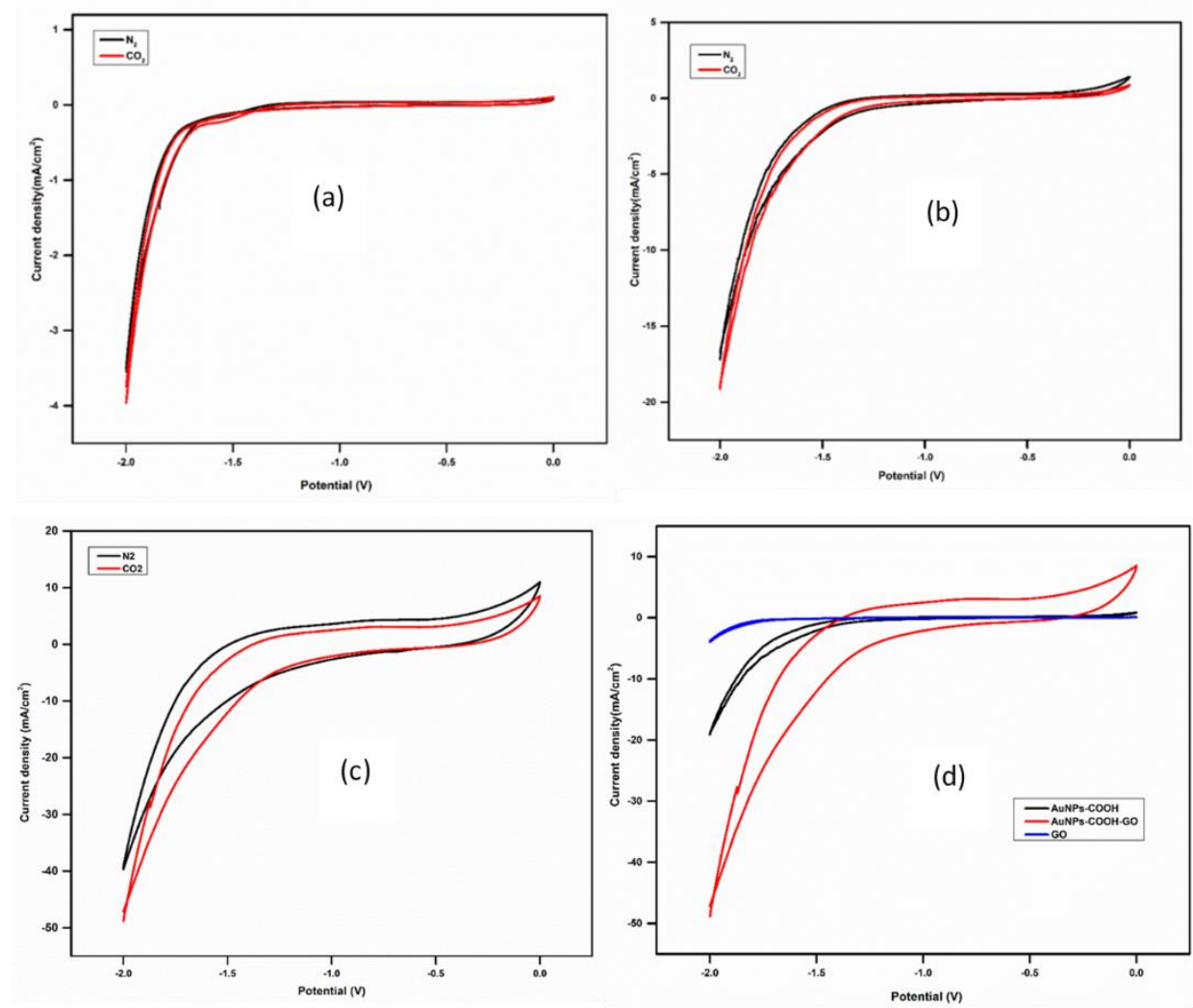

Figure 10. (a) $\mathrm{CVs}$ of $\mathrm{GO}$ in $\mathrm{N}_{2}$ and $\mathrm{CO}_{2}$ saturated $0.5 \mathrm{~mol} / \mathrm{L} \mathrm{KHCO}_{3}$, (b) AuNPs-COOH, (c) $\mathrm{NC}$, and (d) comparison of CVs of $\mathrm{GO}, \mathrm{AuNPs}-\mathrm{COOH}$, and $\mathrm{NC}$ in $\mathrm{CO}_{2}$-saturated $0.5 \mathrm{~mol} / \mathrm{L}$ $\mathrm{KHCO}_{3}$.

Further, we investigated the catalytic effect of GO and AuNPs-COOH individually towards $\mathrm{CO}_{2}$ reduction using $\mathrm{CV}$ measured at $\mathrm{CO}_{2}$ saturated $0.5 \mathrm{M} \mathrm{KHCO}_{3}$ solutions for comparison with NC. Figure 10 shows CVs of GO and AuNPs-COOH catalyst in $\mathrm{N}_{2}$ and $\mathrm{CO}_{2}$ solutions. Current density in $\mathrm{CO}_{2}$ reduction in presence of AuNPs-COOH was slightly higher than in $\mathrm{N}_{2}$, whereas the current density in $\mathrm{CO}_{2}$ reduction by $\mathrm{GO}$ was almost the same in $\mathrm{N}_{2}$ and $\mathrm{CO}_{2}$ saturated solutions. Results suggest that AuNPs-COOH exhibited low activity while GO exhibited negligible activity towards $\mathrm{CO}_{2}$ reduction. Overall, the current density of NC (48 $\left.\mathrm{mA} / \mathrm{cm}^{2}\right)$ was much higher than AuNPs-COOH $\left(19 \mathrm{~mA} / \mathrm{cm}^{2}\right)$ and GO $\left(4 \mathrm{~mA} / \mathrm{cm}^{2}\right)$. In short, our 
results suggest that $\mathrm{NC}$ acted as an efficient electrocatalyst in $\mathrm{CO}_{2}$ reduction compared to $\mathrm{GO}$ and AuNPs-COOH.

\section{CONCLUSIONS}

We demonstrated a novel gold-carbon functionalized graphene oxide nanocomposite for effective catalytic reduction of nitrophenol and electrocatalytic reduction of carbon dioxide, both on accumulation are very harmful to environment and human health. Nitrophenols are among the most common organic contaminants in wastewaters. Because of their toxic nature, it is essential to remediate their presence from water sources. Similarly, $\mathrm{CO}_{2}$ is the primary greenhouse gas emitted by anthropogenic activities. Our method to reduce these environmental contaminants effectively by two strategic methods like heterogeneous catalysis and electrocatalysis strategies also paves the way to effective utilization of gold-carbon nanoparticles/graphene oxide nanocomposites.

\section{ACKNOLWEDGEMENTS}

MO acknowledges VEGA 02/0010/18 (Slovakia) for the financial support. AAM acknowledges the University of Sharjah support of SEED grant (VC-GRC-SR-83-2015), competitive grants (160-2142-029-P and 150-2142-017-P), Organometallic Research Group grant (RISE-046-2016) and Functionalized Nanomaterials Synthesis Lab grant (151-0039).

\section{REFERENCES}

1. Yin, P. T.; Shah, S.; Chhowalla, M.; Lee, K.-B. Design, synthesis, and characterization of graphene-nanoparticle hybrid materials for bioapplications. Chem. Rev. 2015, 115, 2483-2531.

2. Chung, C.; Kim, Y.-K.; Shin, D.; Ryoo, S.-R.; Hong, B. H.; Min, D.-H. Biomedical applications of graphene and graphene oxide. Acc. Chem. Res. 2013, 46, 2211-2224.

3. Karthik, R.; Govindasamy, M.; Chen, S.-M.; Mani, V.; Lou, B.-S.; Devasenathipathy, R.; Hou, Y.-S.; Elangovan, A. Green synthesized gold nanoparticles decorated graphene oxide for sensitive determination of chloramphenicol in milk, powdered milk, honey and eye drops. $J$. Colloid Interface Sci. 2016, 475, 46-56. 
4. Luo, Y.; Kong, F.-Y.; Li, C.; Shi, J.-J.; Lv, W.-X.; Wang, W. One-pot preparation of reduced graphene oxide-carbon nanotube decorated with Au nanoparticles based on prote in for nonenzymatic electrochemical sensing of glucose. Sens. Actuators, B 2016, 234, 625-632.

5. Fu, W. L.; Zhen, S. J.; Huang, C. Z. One-pot green synthesis of graphene oxide/gold nanocomposites as SERS substrates for malachite green detection. Analyst 2013, 138, 3075.

6. Hernández-Sánchez, D.; Villabona-Leal, G.; Saucedo-Orozco, I.; Bracamonte, V.; Pérez, E.; Bittencourt, C.; Quintana, M. Stable graphene oxide-gold nanoparticle platforms for biosens ing applications. Phys. Chem. Chem. Phys. 2018, 20, 1685-1692.

7. Li, D.; Müller, M. B.; Gilje, S.; Kaner, R. B.; Wallace, G. G. Processable aqueous dispersions of graphene nanosheets. Nat. Nanotechnol. 2008, 3, 101-105.

8. Pei, S.; Zhao, J.; Du, J.; Ren, W.; Cheng, H.-M. Direct reduction of graphene oxide films into highly conductive and flexible graphene films by hydrohalic acids. Carbon 2010, 48 , 44664474.

9. Quintana, M.; Vazquez, E.; Prato, M. Organic functionalization of graphene in dispersions. Acc. Chem. Res. 2012, 46, 138-148.

10. Bugárová, N.; Špitálsky, Z.; Mičušik, M.; Bodík, M.; Šiffalovič, P.; Koneracká, M.; Závišová, V.; Kubovčíková, M.; Kajanová, I.; Zat’ovičová, M.; et al. A multifunctional graphene oxide platform for targeting cancer. Cancers 2019, 11, 753.

11. He, H.; Gao, C. Graphene nanosheets decorated with Pd, Pt, Au, and Ag nanoparticles: Synthesis, characterization, and catalysis applications. Sci. China Chem. 2011, 54, 397-404.

12. Yang, H.; Jiang, J.; Zhou, W.; Lai, L.; Xi, L.; Lam, Y.; Shen, Z.; Khezri, B.; Yu, T. Influences of graphene oxide support on the electrochemical performances of graphene oxide- $\mathrm{MnO}_{2}$ nanocomposites. Nanoscale Res. Lett. 2011, 6, 531.

13. Tao, Y.; Dandapat, A.; Chen, L.; Huang, Y.; Sasson, Y.; Lin, Z.; Zhang, J.; Guo, L.; Chen, T. Pdon-Au supra-nanostructures decorated graphene oxide: an advanced electrocatalyst for fuel cell application. Langmuir 2016, 32, 8557-8564.

14. He, S.; Liu, K.-K.; Su, S.; Yan, J.; Mao, X.; Wang, D.; He, Y.; Li, L.-J.; Song, S.; Fan, C. Graphene-based high-effic iency surface-enhanced Raman scattering-active platform for sensitive and multiplex DNA detection. Anal. Chem. 2012, 84, 4622-4627.

15. Khoa, N. T.; Kim, S. W.; Yoo, D.-H.; Kim, E. J.; Hahn, S. H. Size-dependent work function and catalytic performance of gold nanoparticles decorated graphene oxide sheets. Appl. Catal. A 2014, 469, 159-164.

16. Pham, T. A.; Choi, B. C.; Lim, K. T.; Jeong, Y. T. A simple approach for immobilization of gold nanoparticles on graphene oxide sheets by covalent bonding. Appl. Surf. Sci. 2011, 257, 33503357.

17. Zhang, Y.; Liu, S.; Lu, W.; Wang, L.; Tian, J.; Sun, X. In situ green synthesis of Au nanostructures on graphene oxide and their application for catalytic reduction of 4-nitrophenol. Catal. Sci. Technol. 2011, $1,1142$.

18. Zhao, P.; Feng, X.; Huang, D.; Yang, G.; Astruc, D. Basic concepts and recent advances in nitrophenol reduction by gold- and other transition metal nanoparticles. Coord. Chem. Rev. 2015, 287, 114-136.

19. Zhang, M.; Lu, X.; Wang, H.-Y.; Liu, X.; Qin, Y.; Zhang, P.; Guo, Z.-X. Porous gold nanoparticle/graphene oxide composite as efficient catalysts for reduction of 4-nitrophenol. $R S C$ Adv. 2016, 6, 35945-35951.

20. Zhang, X.; Guo, S.-X.; Gandionco, K. A.; Bond, A. M.; Zhang, J. Electrocatalytic carbon dioxide reduction: from fundamental principles to catalyst design. Mater. Today Adv. 2020, 7, 100074.

21. Choi, Y.; Bae, H. S.; Seo, E.; Jang, S.; Park, K. H.; Kim, B.-S. Hybrid gold nanoparticle-reduced graphene oxide nanosheets as active catalysts for highly efficient reduction of nitroarenes. $J$. Mater. Chem. 2011, 21, 15431.

22. Chen, Y.; Li, C. W.; Kanan, M. W. Aqueous $\mathrm{CO}_{2}$ reduction at very low overpotential on oxidederived Au nanoparticles. J. Am. Chem. Soc. 2012, 134, 19969-19972. 
23. Zhu, W.; Michalsky, R.; Metin, Ö.; Lv, H.; Guo, S.; Wright, C. J.; Sun, X.; Peterson, A. A.; Sun, $\mathrm{S}$. Monodis perse Au nanoparticles for selective electrocatalytic reduction of $\mathrm{CO}_{2}$ to CO. J. Am. Chem. Soc. 2013, 135, 16833-16836.

24. Kim, D.; Resasco, J.; Yu, Y.; Asiri, A. M.; Yang, P. Synergistic geometric and electronic effects for electrochemical reduction of carbon dioxide using gold-copper bimetallic nanoparticles. Nat. Commun. 2014, 5, 4948.

25. Zhou, X.; Qiao, J.; Yang, L.; Zhang, J. A review of graphene-based nanostructural materials for both catalyst supports and metal-free catalysts in PEM fuel cell oxygen reduction reactions. Adv. Energy Mater. 2014, 4, 1301523.

26. Fujigaya, T.; Kim, C.; Hamasaki, Y.; Nakashima, N. Growth and deposition of Au nanoclusters on polymer-wrapped graphene and their oxygen reduction activity. Sci. Rep. 2016, 6, 21314.

27. Khoa, N. T.; Kim, S. W.; Yoo, D.-H.; Kim, E. J.; Hahn, S. H. Size-dependent work function and catalytic performance of gold nanoparticles decorated graphene oxide sheets. Appl. Catal. A 2014, 469, 159-164.

28. Ding, M.; Tang, Y.; Star, A. Understanding interfaces in metal-graphitic hybrid nanostructures. $J$. Phys. Chem. Lett. 2012, 4, 147-160.

29. Navalon, S.; Dhakshinamoorthy, A.; Alvaro, M.; Garcia, H. Carbocatalysis by graphene-based materials. Chem. Rev. 2014, 114, 6179-6212.

30. Rogers, C.; Perkins, W. S.; Veber, G.; Williams, T. E.; Cloke, R. R.; Fischer, F. R. Synergistic enhancement of electrocatalytic $\mathrm{CO}_{2}$ reduction with gold nanoparticles embedded in functional graphene nanoribbon composite electrodes. J. Am. Chem. Soc. 2017, 139, 4052-4061.

31. Nguyen, D. L. T.; Lee, C. W.; Na, J.; Kim, M.-C.; Tu, N. D. K.; Lee, S. Y.; Sa, Y. J.; Won, D. H.; Oh, H.-S.; Kim, H.; et al. Mass transport control by surface graphene oxide for selective CO production from electrochemical $\mathrm{CO}_{2}$ reduction. ACS Catal. 2020, 10, 3222-3231.

32. Jlassi, K.; Zavahir, S.; Kasak, P.; Krupa, I.; Mohamed, A. A.; Chehimi, M. M. Emerging clayaryl-gold nanohybrids for efficient electrocatalytic proton reduction. Energy Convers. Manag. 2018, 168, 170-177.

33. Ahmad, A. A. L.; Panicker, S.; Chehimi, M. M.; Monge, M.; Lopez-de-Luzuriaga, J. M.; Mohamed, A. A.; Bruce, A. E.; Bruce, M. R. M. Synthesis of water-soluble gold-aryl nanoparticles with distinct catalytic performance in the reduction of the environmental pollutant 4-nitrophenol. Catal. Sci. Technol. 2019, 9, 6059-6071.

34. Hummers Jr, W. S.; Offeman, R. E. Preparation of graphitic oxide. J. Am. Chem. Soc. 1958, 80, 1339-1339.

35. Abraham M.J.; Van der Spoel, D.; Lindahl, B.; Hess, B.; and the GROMACS development team, GROMACS User Manual version 2019.4, http://www.gromacs.org

36. Schmid, N.; Eichenberger, A. P.; Choutko, A.; Riniker, S.; Winger, M.; Mark, A. E.; Gunsteren, W. F. V. Definition and testing of the GROMOS force-field versions 54A7 and 54B7. Eur. Biophys. J. 2011, 40, 843-856.

37. Lerf, A.; He, H.; Forster, M.; Klinowski, J. Structure of graphite oxide revisited. J. Phys. Chem. B 1998, 102 (23), 4477-4482.

38. Stroet, M.; Caron, B.; Visscher, K. M.; Geerke, D. P.; Malde, A. K.; Mark, A. E. Automated Topology Builder Version 3.0: Prediction of solvation free enthalpies in water and hexane. $J$. Chem. Theory Comput. 2018, 14, 5834-5845.

39. Berendsen, H. J. C.; Postma, J. P. M.; Gunsteren, W. F. V.; Hermans, J. Interaction Models for Water in Relation to Protein Hydration. The Jerusalem Symposia on Quantum Chemistry and Biochemistry Intermolecular Forces 1981,331-342.

40. Darden, T.; York, D.; Pedersen, L. Particle mesh Ewald: AnN $\cdot \log (\mathrm{N})$ method for Ewald sums in large systems. J. Chem. Phys. 1993, $98,10089-10092$.

41. Link, S.; El-Sayed, M. A. Size and temperature dependence of the plasmon absorption of colloidal gold nanoparticles. J. Phys. Chem. B 1999, 103, 4212-4217. 
42. Rawashdeh-Omary, M. A.; Omary, M. A.; Patterson, H. H. Oligomerization of $\mathrm{Au}(\mathrm{CN})_{2}{ }^{-}$and $\mathrm{Ag}(\mathrm{CN})_{2}{ }^{-}$ions in solution via ground-state aurophilic and argentophilic bonding. J. Am. Chem. Soc. 2000, 122, 10371-10380.

43. Tang, H.; Zhao, Y.; Shan, S.; Yang, X.; Liu, D.; Cui, F.; Xing, B. Wrinkle- and edge-adsorption of aromatic compounds on graphene oxide as revealed by atomic force microscopy, molecular dynamics simulation, and density functional theory. Environ. Sci. Technol. 2018, 52, 7689-7697.

44. Almheiri, S.; Ahmad, A. A.; Le Droumaguet, B.; Pires, R.; Mohamed, A. A.; Chehimi, M. M. (2019). Development of latent fingerprints via aryldiazonium tetrachloroaurate salts on copper surfaces: An XPS study. Langmuir, 2020, 36, 74-83.

45. http://sites.cardiff.ac.uk/xpsaccess/reference/gold/ Last accessed 9 November 2020.

46. G. Beamson, D. Briggs (Eds), High-resolution XPS of Organic Polymers: The Scienta ESCA300 Database, John Wiley \& Sons, Chichester, 1992.

47. Saad, A.; Abderrabba, M.; Chehimi, M. M. X-ray induced degradation of surface bound azido groups during XPS analysis. Surf. Interface Anal. 2017, 49, 340-344.

48. Skinner, W. M.; Prestidge, C. A.; Smart, R. S. C. Irradiation effects during XPS studies of Cu (II) activation of zinc sulphide. Surf. Interface Anal., 1996, 24, 620-626.

49. Hinrichs, K.; Roodenko, K.; Rappich, J.; Chehimi, M. M.; Pinson, J. in Aryl Diazonium Salts: New Coupling Agents in Polymer and Surface Science, Chehimi, M.M. (Ed.); Wiley-VCH: Weinheim, Germany, 2012, pp 84-91.

50. Mesnage, A. ; Lefèvre, X. ; Jégou, P.; Deniau, G.; Palacin, S. Spontaneous grafting of diazonium salts: chemical mechanism on metallic surfaces. Langmuir 2012, 28, 11767-11778.

51. Laurentius, L.; Stoyanov, S. R.; Gusarov, S.; Kovalenko, A.; Du, R.; Lopinski, G. P.; Mcdermott, M. T. Diazonium-derived aryl films on gold nanoparticles: evidence for a carbon-gold covalent bond. ACS Nano 2011, 5 , 4219-4227.

52. Song, K.-W.; Park, M.-H.; Kim, T.-H.; Lim, S.-H.; Yang, C.-W. UV Enhanced synthesis of high density Au coated $\mathrm{ZnO}$ nanocomposite. J. Nanosci. Nanotechnol. 2014, 14, 8766-8770.

53. Zhan, W.; Wang, J.; Wang, H.; Zhang, J.; Liu, X.; Zhang, P.; Chi, M.; Guo, Y.; Guo, Y.; Lu, G.; et al. Crystal structural effect of $\mathrm{AuCu}$ alloy nanoparticles on catalytic $\mathrm{CO}$ oxidation. J. Am. Chem. Soc. 2017, 139, 8846-8854.

54. Radic, S.; Geitner, N. K.; Podila, R.; Käkinen, A.; Chen, P.; Ke, P. C.; Ding, F. Competitive binding of natural amphiphiles with graphene derivatives. Sci. Rep. 2013,3 (1).

55. Tang, H.; Zhao, Y.; Shan, S.; Yang, X.; Liu, D.; Cui, F.; Xing, B. Theoretical insight into the adsorption of aromatic compounds on graphene oxide. Environ. Sci.: Nano 2018, 5 , 2357-2367.

56. Wunder, S.; Lu, Y.; Albrecht, M.; Ballauff, M. Catalytic activity of faceted gold nanoparticles studied by a model reaction: evidence for substrate-induced surface restructuring. ACS Catal. 2011, 1, 908-916.

57. Kim, J.; Kim, D. H.; Kwon, D. W.; Ha, H. P. Rational selection of $\mathrm{Fe}_{2} \mathrm{~V}_{4} \mathrm{O}_{13}$ over $\mathrm{FeVO}_{4}$ as a preferred active site on Sb-promoted $\mathrm{TiO}_{2}$ for catalytic NOX reduction with $\mathrm{NH}_{3}$. Catal. Sci. Technol. 2018, 8, 4774-4787.

58. Hervés, P.; Pérez-Lorenzo, M.; Liz-Marzán, L. M.; Dzubiella, J.; Lu, Y.; Ballauff, M. Catalysis by metallic nanoparticles in aqueous solution: model reactions. Chem. Soc. Rev. 2012, 41, 5577.

59. Luna, P. D.; Hahn, C.; Higgins, D.; Jaffer, S. A.; Jaramillo, T. F.; Sargent, E. H. What would it take for renewably powered electrosynthesis to displace petrochemical processes? Science $\mathbf{2 0 1 9}$, 364 (6438).

60. Nielsen, D. U.; Hu, X.-M.; Daasbjerg, K.; Skrydstrup, T. Chemically and electrochemically catalysed conversion of $\mathrm{CO}_{2}$ to $\mathrm{CO}$ with follow-up utilization to value-added chemicals. Nat. Catal. 2018, 1, 244-254.

61. Sheng, W.; Kattel, S.; Yao, S.; Yan, B.; Liang, Z.; Hawxhurst, C. J.; Wu, Q.; Chen, J. G. Electrochemical reduction of $\mathrm{CO}_{2}$ to synthes is gas with controlled $\mathrm{CO} / \mathrm{H}_{2}$ ratios. Energy Environ. Sci. 2017, 10, 1180-1185. 
62. Zheng, X.; Ji, Y.; Tang, J.; Wang, J.; Liu, B.; Steinrück, H.-G.; Lim, K.; Li, Y.; Toney, M. F.; Chan, K.; et al. Theory-guided $\mathrm{Sn} / \mathrm{Cu}$ alloying for efficient $\mathrm{CO}_{2}$ electroreduction at low overpotentials. Nat. Catal. 2018, 2(1), 55-61.

63. Lu, Q.; Jiao, F. Electrochemical $\mathrm{CO}_{2}$ reduction: electrocatalyst, reaction mechanism, and process engineering. Nano Energy 2016, 29, 439-456.

64. Boot-Handford, M. E.; Abanades, J. C.; Anthony, E. J.; Blunt, M. J.; Brandani, S.; Dowell, N. M.; Fernández, J. R.; Ferrari, M.-C.; Gross, R.; Hallett, J. P.; et al. Carbon capture and storage update. Energy Environ. Sci. 2014, 7 (1), 130-189.

65. Albo, J.; Alvarez-Guerra, M.; Castaño, P.; Irabien, A. Towards the electrochemical conversion of carbon dioxide into methanol. Green Chem. 2015, 17 (4), 2304-2324.

66. Dominguez-Ramos, A.; Singh, B.; Zhang, X.; Hertwich, E.; Irabien, A. Global warming footprint of the electrochemical reduction of carbon dioxide to formate. J. Cleaner Prod. 2015, 104, 148155.

\section{$\underline{\text { TOC Graphic }}$}

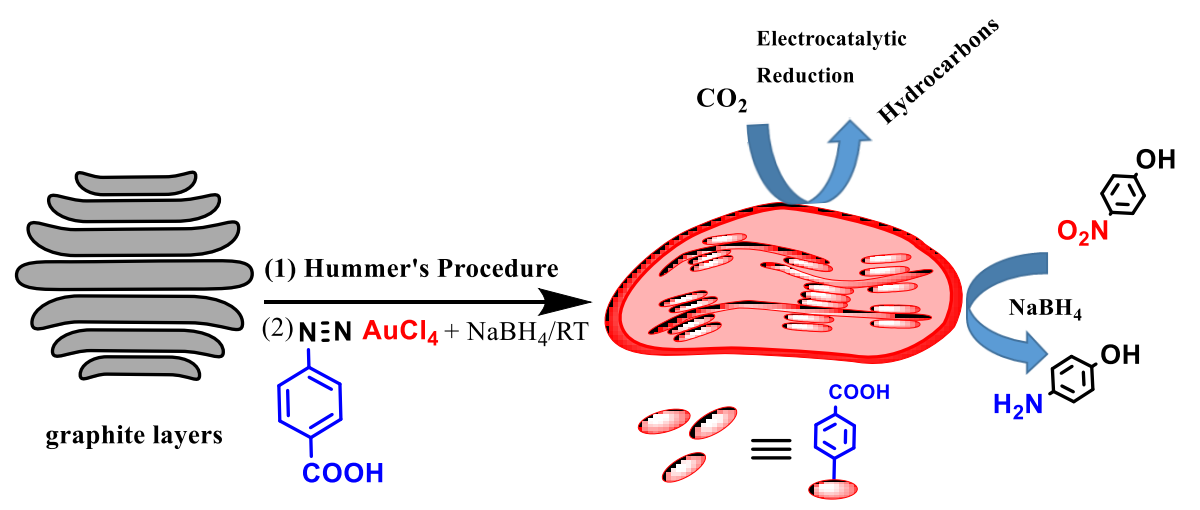

